\title{
Active megadetachment beneath the western United States
}

\author{
Brian Wernicke, ${ }^{1}$ James L. Davis, ${ }^{2}$ Nathan A. Niemi, ${ }^{3}$ Peter Luffi, ${ }^{1,4}$ \\ and Sunil Bisnath ${ }^{2,5}$ \\ Received 6 September 2007; revised 21 March 2008; accepted 14 August 2008; published 21 November 2008.
}

[1] Geodetic data, interpreted in light of seismic imaging, seismicity, xenolith studies, and the late Quaternary geologic history of the northern Great Basin, suggest that a subcontinental-scale extensional detachment is localized near the Moho. To first order, seismic yielding in the upper crust at any given latitude in this region occurs via an M7 earthquake every 100 years. Here we develop the hypothesis that since 1996, the region has undergone a cycle of strain accumulation and release similar to "slow slip events" observed on subduction megathrusts, but yielding occurred on a subhorizontal surface 5-10 times larger in the slip direction, and at temperatures $>800^{\circ} \mathrm{C}$. Net slip was variable, ranging from 5 to $10 \mathrm{~mm}$ over most of the region. Strain energy with moment magnitude equivalent to an M7 earthquake was released along this "megadetachment," primarily between 2000.0 and 2005.5. Slip initiated in late 1998 to mid-1999 in northeastern Nevada and is best expressed in late 2003 during a magma injection event at Moho depth beneath the Sierra Nevada, accompanied by more rapid eastward relative displacement across the entire region. The event ended in the east at 2004.0 and in the remainder of the network at about 2005.5. Strain energy thus appears to have been transmitted from the Cordilleran interior toward the plate boundary, from high gravitational potential to low, via yielding on the megadetachment. The size and kinematic function of the proposed structure, in light of various proxies for lithospheric thickness, imply that the subcrustal lithosphere beneath Nevada is a strong, thin plate, even though it resides in a high heat flow tectonic regime. A strong lowermost crust and upper mantle is consistent with patterns of postseismic relaxation in the southern Great Basin, deformation microstructures and low water content in dunite xenoliths in young lavas in central Nevada, and high-temperature microstructures in analog surface exposures of deformed lower crust. Large-scale decoupling between crust and upper mantle is consistent with the broad distribution of strain in the upper crust versus the more localized distribution in the subcrustal lithosphere, as inferred by such proxies as low $\mathrm{P}$ wave velocity and mafic magmatism.

Citation: Wernicke, B., J. L. Davis, N. A. Niemi, P. Luffi, and S. Bisnath (2008), Active megadetachment beneath the western United States, J. Geophys. Res., 113, B11409, doi:10.1029/2007JB005375.

\section{Introduction}

[2] Where plate interactions involving continents exert stresses normal to the boundary (either as deviatoric compression or extension), deformation is observed at distances of order $1000 \mathrm{~km}$ into the continental interior [e.g., Molnar and Tapponnier, 1975; Schellart and Lister, 2005]. At issue

\footnotetext{
${ }^{1}$ Division of Geological and Planetary Sciences, California Institute of Technology, Pasadena, California, USA.

${ }^{2}$ Harvard-Smithsonian Center for Astrophysics, Cambridge, Massachusetts, USA.

${ }^{3}$ Department of Geological Sciences, University of Michigan, Ann Arbor, Michigan, USA.

${ }^{4}$ Now at Department of Earth Science, Rice University, Houston, Texas, USA.

${ }^{5}$ Now at Department of Earth and Space Science and Engineering, York University, Toronto, Canada.

Copyright 2008 by the American Geophysical Union. 0148-0227/08/2007JB005375\$09.00
}

in continental dynamics is the location and function of tectonic elements that control the transfer of energy across these broad plate boundary deformation zones. These elements may include intraplate faults bounding a relatively small number of rigid lithospheric blocks [Tapponnier et al., 2001], large regions of continuous deformation [Gan et al., 2007], and regional decoupling horizons that accommodate strong vertical variations in strain [Oldow et al., 1990].

[3] Physical models that treat the continental lithosphere as a thin, viscous sheet [England and McKenzie, 1982] suggest that the width of plate boundary deformation scales approximately with the length of the plate boundary along which either contractional or extensional boundary velocities are applied [England et al., 1985]. These models are thus successful in predicting the dimensions and certain other aspects of some continental orogens, but for mathematical convenience parameterize the lithosphere in terms of a power law that represents a vertical average of 
constitutive behaviors determined from laboratory experiments [Sonder and England, 1986]. These models explicitly neglect any effects that might result from horizontal shearing between layers within the lithosphere, as may be expected given potentially strong vertical variations in temperature, composition and fluid activity. Indeed, in cross-sectional models that allow for the possibility of decoupling between layers, the distribution of lithospheric strain, including the width of the zone of deformation in the upper crust and the development of subhorizontal detachments, is strongly sensitive to rheological variations with depth [Buck, 1991; Weinberg et al., 2007]. Accordingly, the assumption that various rheological layers are well coupled from bottom to top and that continental lithosphere effectively behaves as a single sheet is open to question. In any event, from an experimental or theoretical point of view, the importance of decoupling horizons, the strength of the seismogenic layer versus deep crust, and the strength of deep crust versus upper mantle remain controversial [e.g., Jackson, 2002; Watts and Burov, 2003; Flesch et al., 2007].

[4] From the perspective of structural geology, regional decoupling within the uppermost parts of the lithosphere is well established by the widespread occurrence of accretionary complexes involving upper continental crust along convergent plate boundaries (e.g., western Alps and Lesser Himalaya), and within intraplate marginal fold belts (e.g., the sub-Andean zone and the Cordilleran fold and thrust belt). However, in most of the major active continental orogens, including the North American Cordillera, the central Andes, the Aegean region, Iran and Tibet, plate boundary deformation affects the whole lithospheric column and is of subcontinental dimensions, and the role of decoupling horizons at depth within these regions is still a matter of vigorous debate. Many workers have cited evidence favoring significant lateral transfer of horizontal strain along large-scale shear zones in the internal portions of orogenic belts, in both horizontal extension and contraction [e.g., Cook et al., 1979; Wernicke, 1985; Burchfiel et al., 1989; Reston, 1990; Axen et al., 1998; DeCelles et al., 2001], including the suggestion that wholesale detachment of the orogenic crust from the upper mantle is a general property of orogens [Oldow et al., 1990]. Primarily on the basis of arguments involving relationships between topography, tilt, flexure, and strain of the upper crust, a number of workers have even suggested large-scale fluid behavior of deep crust (e.g., Taber [1927], J. K. Sales, as cited by Stewart [1978], Block and Royden [1990], Wernicke [1990], Kruse et al. [1991], and Beaumont et al. [2001]).

[5] The northern Great Basin is an 800-km-wide region of high heat flow, thin crust, thin lithosphere and active deformation in both extension and right-lateral shear, accommodating about $25 \%$ of total Pacific-North America relative plate motion [Smith, 1978; Lachenbruch and Sass, 1978; Bennett et al., 1999]. Subhorizontal decoupling at or near the base of the crust associated with mafic magmatism has long been suspected, primarily on the basis of (1) a strong, continuous seismic reflection Moho with very bright reflections localized along it [Klemperer et al., 1986; Hauser et al., 1987; Jarchow et al., 1993; Suetnova et al., 1993]; (2) high seismic reflectivity in the lower crust, especially beneath the western $2 / 3$ of the province in Nevada [Allmendinger et al., 1987; Hauge et al., 1987;
Holbrook et al., 1991]; and (3) widespread young mafic volcanism [Christiansen and Yeats, 1992].

[6] The issues of energy transfer and decoupling can be addressed in this region by integrating a wide range of seismic and geologic data with a new class of observation that bears strongly on them: a decade-long kinematic image of the entire $\sim 1000 \mathrm{~km}$ width of the deforming North American plate, using continuous GPS. Until recently, GPS networks with the temporal resolution necessary for detecting velocity changes have targeted relatively narrowaperture (of order $100 \mathrm{~km}$ ) processes associated with rapidly moving plate boundary faults. Continuous GPS data from the oldest 18 sites of the Basin and Range Geodetic Network (BARGEN), installed in 1996 and 1997, has yielded the first kinematic image of a wide plate boundary deformation zone with spatial and temporal sampling appropriate for the detection of subcontinental-scale changes in velocity [Bennett et al., 1998; Wernicke et al., 2000; Davis et al., 2003]. The image suggests that large, coherent changes in crustal velocity affect the western $500 \mathrm{~km}$ of the geodetic transect [Davis et al., 2006], perhaps analogous to slow slip events (SSEs) observed near subduction interfaces. We develop the hypothesis that these velocity changes, as for subduction zone SSEs, result from strain release along a zone of decoupling, or intracontinental megadetachment, localized near the Moho beneath the Basin and Range. A $>1000$-km-wide, 850-site network across the western United States and Alaska, constructed under the auspices of the EarthScope program, is certain to yield a much more detailed picture of any coherent, large-scale velocity changes in the Cordillera over the next decade, robustly testing this "megadetachment hypothesis" for intraplate strain.

\section{Geological and Geophysical Constraints 2.1. Late Quaternary Faulting in the Upper Crust}

[7] The northern Basin and Range province is a diffuse array of active strike-slip and normal faults along the Pacific-North America transform plate boundary. It accommodates $12 \mathrm{~mm} \mathrm{a}^{-1}(25 \%)$ of Pacific-North America transtensional motion, and extends as far as $1000 \mathrm{~km}$ inboard from the plate boundary to the Great Salt Lake region of northern Utah (Figure 1). Basin and Range normal faults are dominantly $\mathrm{N}$ to $\mathrm{NNE}$ striking with $\mathrm{E}-\mathrm{W}$ to WNW-ESE slip across the eastern 3/4 of the region. Along the western $1 / 4$ in westernmost Nevada and eastern California, strike-slip faults and pull-apart basin geometries are prevalent, comprising a zone of NNW right-lateral shear known as the Walker Lane fault system [Wesnousky, 2005a] or, where it enters California toward the south, the eastern California shear zone (Figure 1) [Dokka and Travis, 1990; Miller et al., 2001]. At large scale, the northern Basin and Range is a right-stepping pull-apart system. The eastern California shear zone/Walker Lane fault system accommodates transform motion, which from south to north is progressively transferred into extension [Oldow et al., 2001; Oldow, 2003; Bennett et al., 2003; Wesnousky, 2005a; Hammond and Thatcher, 2007].

[8] Geological studies over the last two decades have shown that late Quaternary slip rates on range-bounding faults are typically near $0.3 \mathrm{~mm} \mathrm{a}^{-1}$ (recent summaries by 


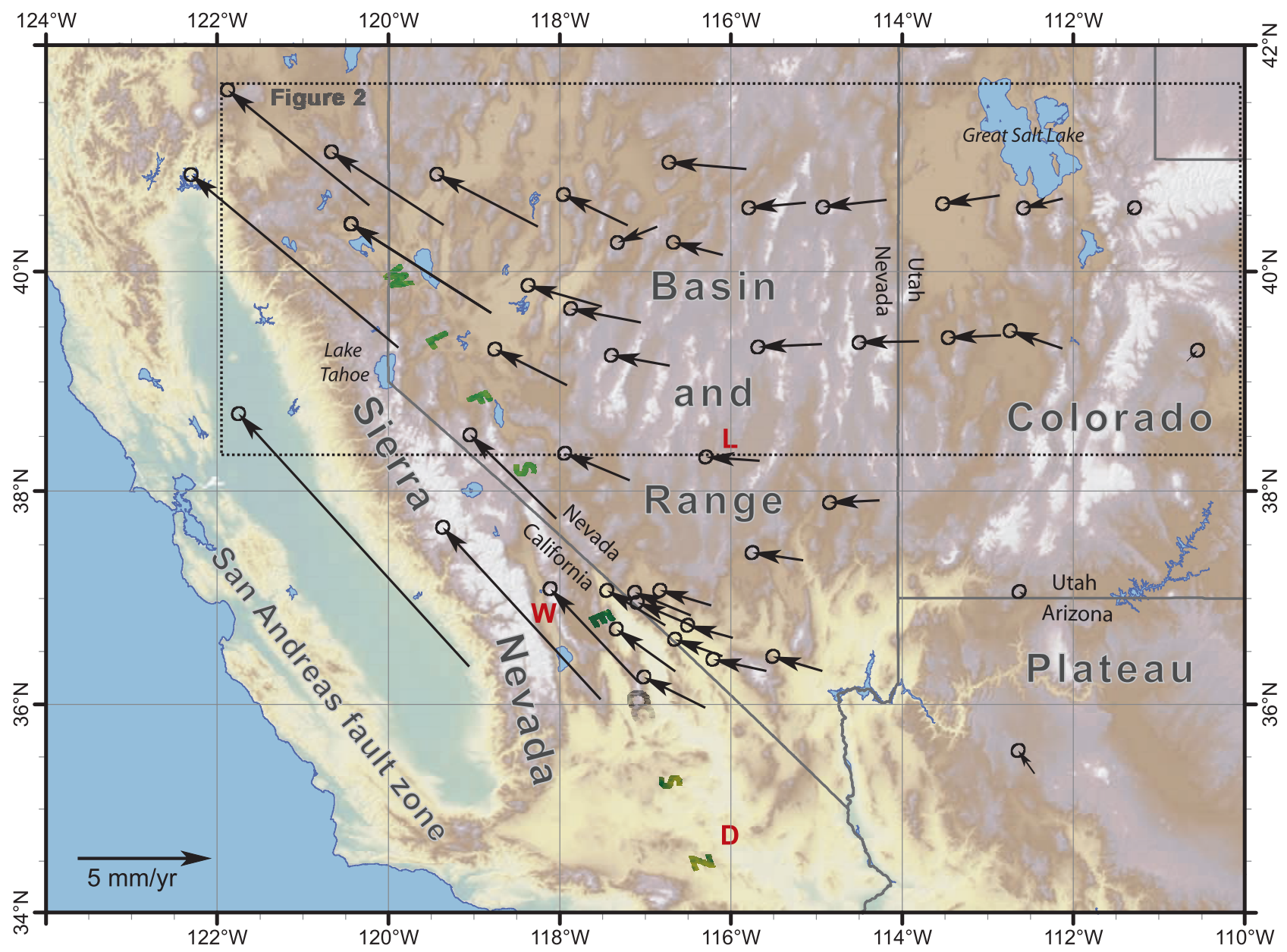

Figure 1. Colored relief map showing average BARGEN velocity field [after Davis et al., 2006] (some BARGEN site velocities near the Yucca Mountain area omitted to reduce clutter). Box shows location of Figure 2. WLFS, Walker Lane fault system; ECSZ, eastern California shear zone. Red letters indicate locations of xenolith-bearing volcanic fields: D, Dish Hill, California; L, Lunar Craters, Nevada; W, Waucoba, Owens Valley area, California.

Niemi et al. [2004], Friedrich et al. [2003], and Wesnousky et al. [2005]), in good agreement with long-term (10 Ma) estimates derived from reconstructing the geological offset along a typical range front [Thompson and Burke, 1973]. Along some faults (e.g., the Wasatch fault along the eastern margin of the region), Holocene clustering of events indicate transient $(10,000$ years $)$ geologic slip rates $>1 \mathrm{~mm} \mathrm{a}^{-1}$, but even in this case the long-term rate $(100,000$ years $)$ is still near $0.3 \mathrm{~mm} \mathrm{a}^{-1}$ [e.g., Friedrich et al., 2003]. In the Walker Lane fault system/eastern California shear zone, long-term slip rates on individual faults are somewhat larger. As strain becomes more concentrated toward the south and active extension becomes subordinate to shear, individual strike-slip faults have late Quaternary slip rates an order of magnitude greater than the normal faults, in the $3 \mathrm{~mm} \mathrm{a}^{-1}$ range [Reheis and Sawyer, 1997; Wesnousky, 2005b; Frankel et al., 2007].

[9] Over the last 100 years, seismic strain release in the northern Great Basin has been concentrated in a longitudinal band of historic ruptures known as the central Nevada seismic belt (Figure 2a) [Wallace, 1984; Bell et al., 2004]. Within this belt, earthquakes are typically M7 with hori- zontal coseismic displacements of 1 to $3 \mathrm{~m}$ on ruptures $50 \mathrm{~km}$ long. Slip rates in the $0.3 \mathrm{~mm} \mathrm{a}^{-1}$ range predict longterm earthquake recurrence intervals of 10,000 years for individual faults, in good agreement with paleoseismic studies [Caskey et al., 2004; Bell et al., 2004; Friedrich et al., 2004; Wesnousky et al., 2005]. The shortest recurrence intervals of $\sim 2500$ years occur during clusters and associated high transient slip rates [e.g., Machette et al., 1991; Friedrich et al., 2003, 2004]. As a whole paleoseismic data suggest concentrated strain release in the central Nevada belt and along the eastern and westernmost fault zones over the last 50,000 years [Wesnousky et al., 2005]. At the scale of 100,000 years, proxies for overall displacement history (scarp morphology and the presence and size of basal facets on range fronts) suggest somewhat less concentrated strain [dePolo and Anderson, 2000]. At the million-year scale the uniformity of range sizes and basin depths constitute perhaps the clearest example of distributed tectonic strain on the globe [Stewart, 1978]. Although paleoseismic investigations are not yet definitive, they are consistent with the hypothesis that strain release at the 100-year timescale is focused in longitudinal belts that 

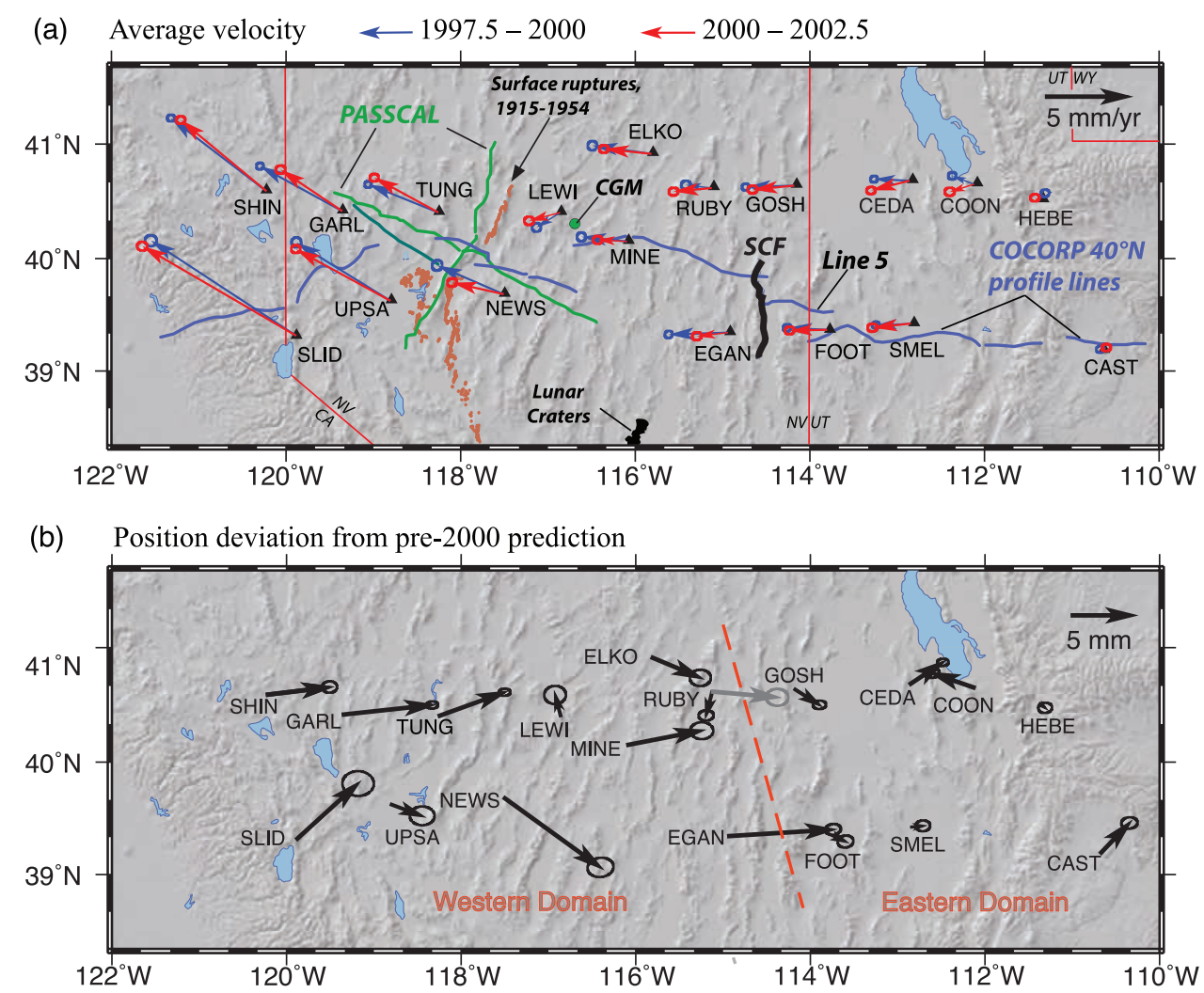

(c) Difference between pre-2000 velocity and 2003.0 to 2004.0 velocity

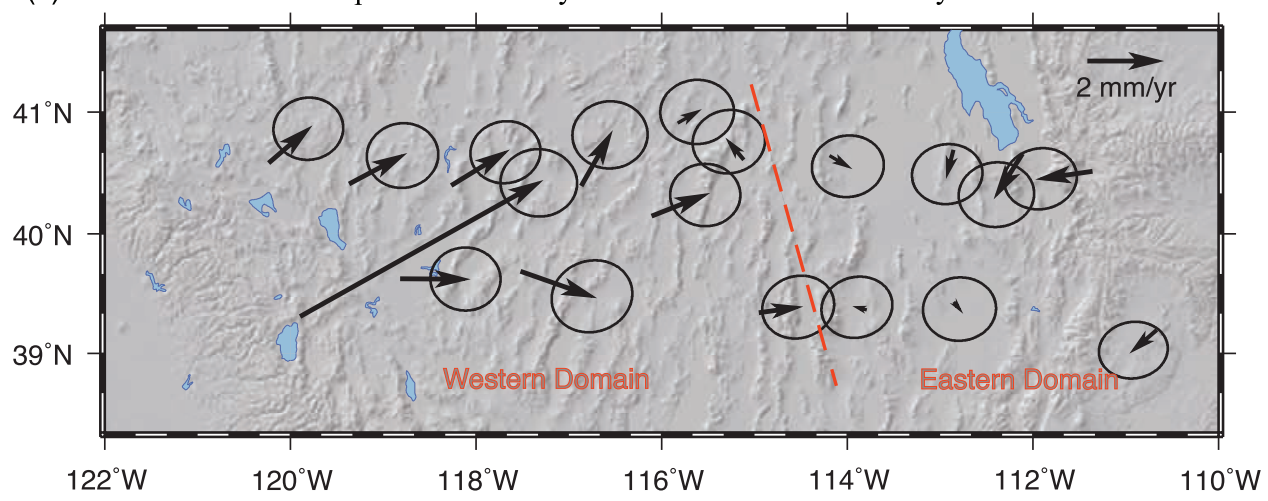

Figure 2. Map showing velocity and displacement fields associated with transient motions of the first 18 BARGEN sites installed across northern Great Basin, using the geodetic network solution of Davis et al. [2006]. (a) Average velocities for intervals 1997.5 to 2000.0 (blue arrows) and 2000.0 to 2002.5 (red arrows). Also shown are position of COCORP $40^{\circ} \mathrm{N}$ profile lines (blue), PASSCAL survey lines (green); traces of central Nevada seismic belt surface ruptures (brown) after Bell et al. [2004]; surface trace of Schell Creek fault (SCF); and the location of Cortez gold mine open pit operation (CGM). (b) Deviations from position predicted on the basis of pre-2000 site velocities [Davis et al. 2006], showing approximate boundary between eastern and western geodetic domains; deviations of sites CEDA and COON have been corrected for lake loading effects [Elósegui et al., 2003] but likely still contain unmodeled hydrological signal from groundwater effects in the metropolitan area around Salt Lake City. Gray arrow for site RUBY shows deviation from pre-1998.5 estimated velocity. (c) Difference between 2003.0 to 2004.0 velocity and 1997.5 to 2000 average velocity (compare Figure 4 of Davis et al. [2006]).

migrate with time across the province [Wallace, 1987; Bell et al., 2004].

\subsection{Average Geodetic Velocities}

[10] Average horizontal geodetic velocities (relative to North America) rise from near zero on the Colorado Plateau to $3 \mathrm{~mm} \mathrm{a}^{-1}$ oriented due west near the Nevada-Utah border (Figure 1) [Bennett et al., 1998, 1999, 2003; Wernicke et al., 2000; Thatcher et al., 1999; Hammond and Thatcher, 2004; Davis et al., 2006]. They remain relatively constant across eastern Nevada, and rotate northwestward and progressively 


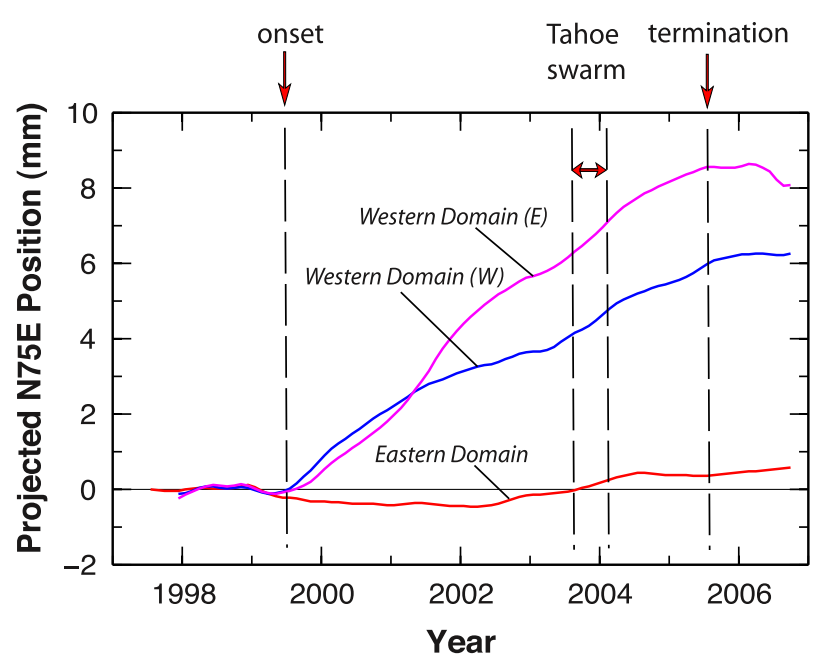

Figure 3. Regionally averaged (stacked) nonlinear deviations of $\mathrm{N}^{\circ} 5^{\circ} \mathrm{E}$ position. Red indicates eastern domain sites (GOSH, FOOT, CAST, SMEL, COON, CEDA, HEBE, RUBY); purple indicates western domain sites ELKO, MINE, EGAN; blue indicates western domain sites NEWS, TUNG, UPSA, GARL, SHIN. Only data from a common epoch range (1997.9-2006.7) were used. The time series shown are an update of the time series in Figure $3 \mathrm{c}$ of Davis et al. [2006], using BARGEN data acquired through November 2006 and analyzed with the GAMIT/GLOBK analysis package version 10.3. The time series differ in that seasonal variation, previously modeled as sinusoidal amplitudes that varied in piecewise-continuous linear fashion, are here modeled as a continuously varying stochastic process and estimated using a Kalman filter.

increase in magnitude up to $12 \mathrm{~mm} \mathrm{a}^{-1}$ across the Walker Lane fault system, with the highest strain rates near the western margin.

[11] Between $40^{\circ} \mathrm{N}$ and $41^{\circ} \mathrm{N}$ latitude, there are about 20 active range-bounding structures exposed across orogenic strike, over a distance of $800 \mathrm{~km}$ (Figure 1; see also Figure 14). Each fault would have to accommodate an average of $0.6 \mathrm{~mm} \mathrm{a}^{-1}$ of horizontal displacement to achieve a net late Quaternary displacement rate of $12 \mathrm{~mm} \mathrm{a}^{-1}$. Comparisons of the geodetic and geologic velocity fields in the central Nevada seismic belt [Bell et al., 2004], across a broad region of northern Nevada [Wesnousky et al., 2005] and in southern Nevada [Wernicke et al., 2004] all indicate that the deformation rate estimated by summing late Quaternary fault displacements (averaging over 20,000 to 50,000 years) are at least a factor of 2 less than average GPS velocities, suggesting either (1) "off fault" strain release that is too diffuse to detect using paleoseismic methods or (2) temporal variations in the crustal velocity field [Bell et al., 2004; Pancha et al., 2006].

\subsection{Variations in Geodetic Velocity}

\subsubsection{General Characteristics}

[12] Continuous GPS measurements across the northern Basin and Range constitute the first image of subcontinentalscale variations in velocity and strain rate in an orogenic belt [Davis et al., 2006]. For the first 3 years of observation (1996.5-1999.5), most BARGEN site velocities were rel- atively constant [Wernicke et al., 2000], with the accuracy of the velocity estimates of $0.2 \mathrm{~mm} \mathrm{a}^{-1}$ at one standard deviation [Davis et al., 2003]. Beginning in mid-1999, the westward motion (in a North American reference frame) for many of the sites in the western part of the network began to slow (Figure 2a). By 2004.0, the deviations of site position from that predicted by pre-2000 velocities were as high as $10 \pm 1 \mathrm{~mm}$ for some sites (Figure 2b) [Davis et al., 2006], primarily in the east component of position, indicating changes in velocity well above error. These deviations defined two spatial domains (hereafter informally referred to as the "western domain" and "eastern domain") separated by a NNW trending boundary in eastern Nevada, located near site RUBY to the north and between sites EGAN and FOOT to the south (Figures $2 \mathrm{~b}$ and $2 \mathrm{c}$ ).

[13] Given these spatial variations, we can assess the average behavior of deviations in position using regional "stacks" of the time series of position deviation, where we sum the time series and divide the displacement by the number of sites (Figure 3) [Davis et al., 2006]. With important exceptions in individual site behavior discussed in section 2.3.2, the deviation between eastern and western sites began at about 1999.5. After 2002, the eastern part of the western domain began to develop somewhat larger deviations than the western part. In late 2003, sites in all domains were particularly slow, coeval with a deep crustal earthquake swarm near Lake Tahoe discussed further in section 2.4. As of 2005.5, sites WSW of the boundary developed eastward deviations averaging $7 \mathrm{~mm}$, while those to the east of it had relatively linear velocities and deviations of $<1 \mathrm{~mm}$ (Figure 3 ). After 2005.5, on average sites in all domains appear to have velocities similar to those prior to 2000.0. A rigorous quantitative comparison of post2005.5 velocities with pre-2000 velocities must await acquisition and processing of an additional year of data.

\subsubsection{Site-by-Site Characteristics}

[14] To analyze the pattern of variation in velocity that occurred near 1999.5 on a site-by-site basis, we compare linear regressions of filtered time series (see discussion of methods by Davis et al. [2006] for details on data analysis procedures) on all 18 sites for the periods 1997.5 to 2000.0 and 2000.0 to 2002.5 . We plot velocity as a function of distance oriented $\mathrm{N} 70^{\circ} \mathrm{E}$, roughly normal to the boundary between the eastern and western domains, and normal to the transform plate boundary at these latitudes (Figures 2 and 4). We separate velocity into two latitudinal transects, a southern one comprising sites centered on latitude $39.5^{\circ} \mathrm{N}$ (Figure $4 \mathrm{a}$ ) and a northern one centered on latitude $40.5^{\circ} \mathrm{N}$ (Figure $4 \mathrm{~b}$ ), and show velocity differences for the two epochs as a single plot (Figure 4c).

[15] Average west velocity difference ranges from $+0.7 \mathrm{~mm} \mathrm{a}^{-1}$ (RUBY) to $-1.7 \mathrm{~mm} \mathrm{a}^{-1}$ (EGAN). A salient aspect of these data is that the seven eastern domain sites (east of and including FOOT) have net changes (either positive or negative) that are distinctly smaller than western domain sites, with the largest change (EGAN) immediately west of FOOT (Figure 4c). The average change is $0.3 \mathrm{~mm} \mathrm{a}^{-1}$ for the seven eastern domain sites and $0.7 \mathrm{~mm} \mathrm{a}^{-1}$ for western domain sites. Despite the high degree of activity in terms of both extensional and compressional transient strains, the velocities of the eastern Nevada sites averaged over the entire interval (1997.5 to 2002.5) are remarkably 

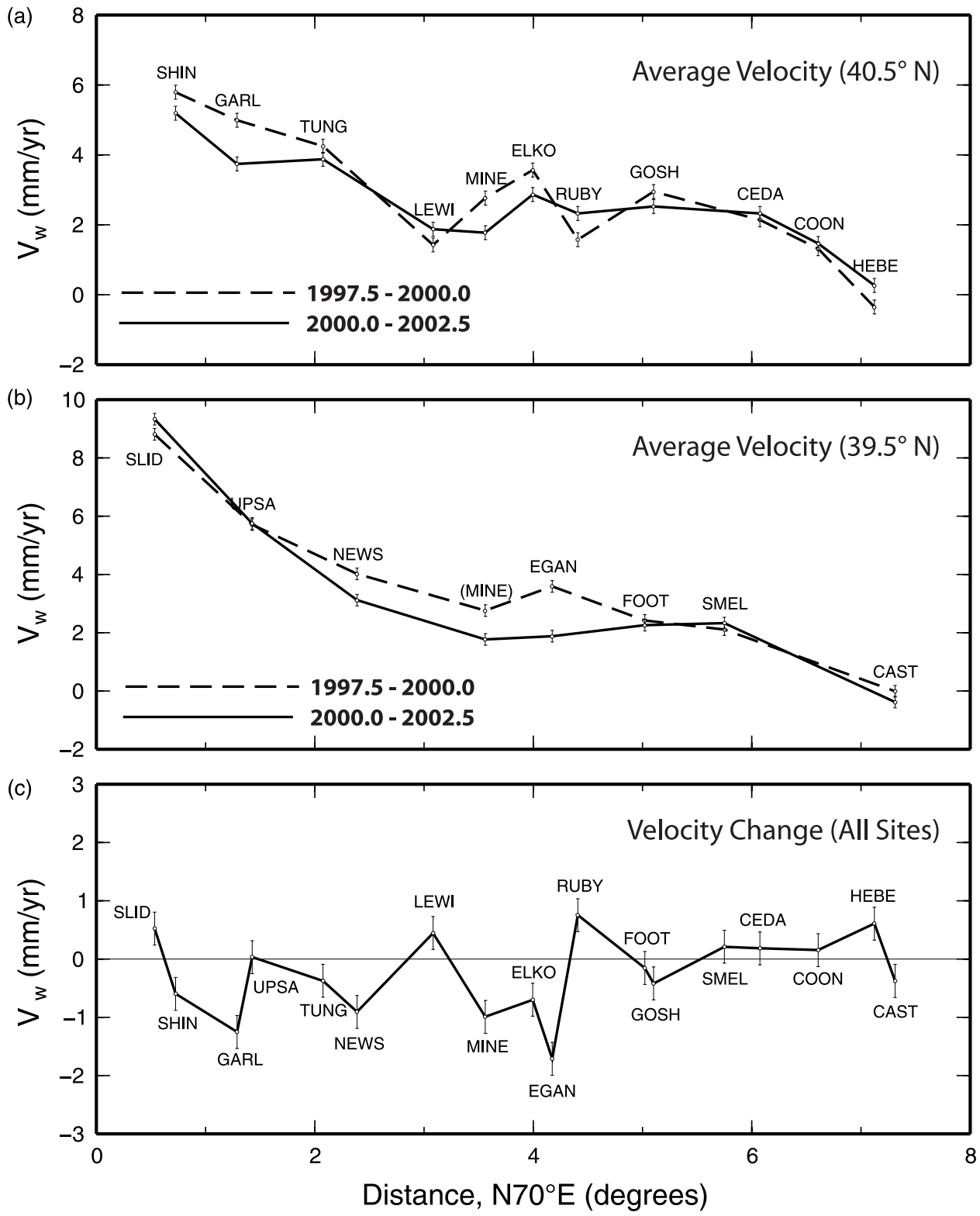

Figure 4. West component of velocity relative to North America versus position projected along $\mathrm{N} 70^{\circ} \mathrm{E}$. (a) Northern transect; (b) southern transect, including site MINE from the northern transect; (c) difference in west component of velocity for all sites.

similar, exhibiting no systematic regional variation (Figure 1) [Bennett et al., 2003; Hammond and Thatcher, 2004]. Thus there appears to be no correlation between average regional strain rate and the level of transient deformation.

[16] The variations in velocity are also evident in the time series of the east component of baseline length between pairs of sites on different sides of the boundary between the eastern and western domains (Figure 5). The marked slowing of sites such as NEWS, MINE, EGAN and ELKO versus the relatively constant velocity of western Utah sites such as FOOT, SMEL and CEDA resulted in net east-west shortening of these baselines from 2000.0 to 2004.0 (e.g., EGAN-FOOT, Figure 4b). The shortening is also apparent from the positive slopes of baseline pairs MINE-GOSH and EGAN-FOOT on Figures $4 \mathrm{a}$ and $4 \mathrm{~b}$, respectively. Shortening is followed by a return to extension between 2004.0 and
2005.5. For the sites opposite to the general pattern of slowing, LEWI exhibits only a slight increase in velocity that is well within error, and as discussed below its average velocity is already low. Although SLID shows a fairly large increase in velocity, within a year that increase is more than erased by six months of extreme slowing described in section 2.4 .

[17] RUBY's large increase is highly anomalous compared with any of the other 17 sites. Its origin appears to be a function of the time intervals chosen for calculating velocity, rather than the overall form of the time series. The time series for baseline pair RUBY-GOSH shows $3 \mathrm{~mm}$ of shortening at $1 \mathrm{~mm} \mathrm{a}^{-1}$ from 1998.0 to 2000.5 , and very little change thereafter (Figure 5a). Like other western domain sites, RUBY moved eastward relative to western Utah, but the motion occurred 2 years earlier than it did for 
(a)

(b)

(c)

(d)

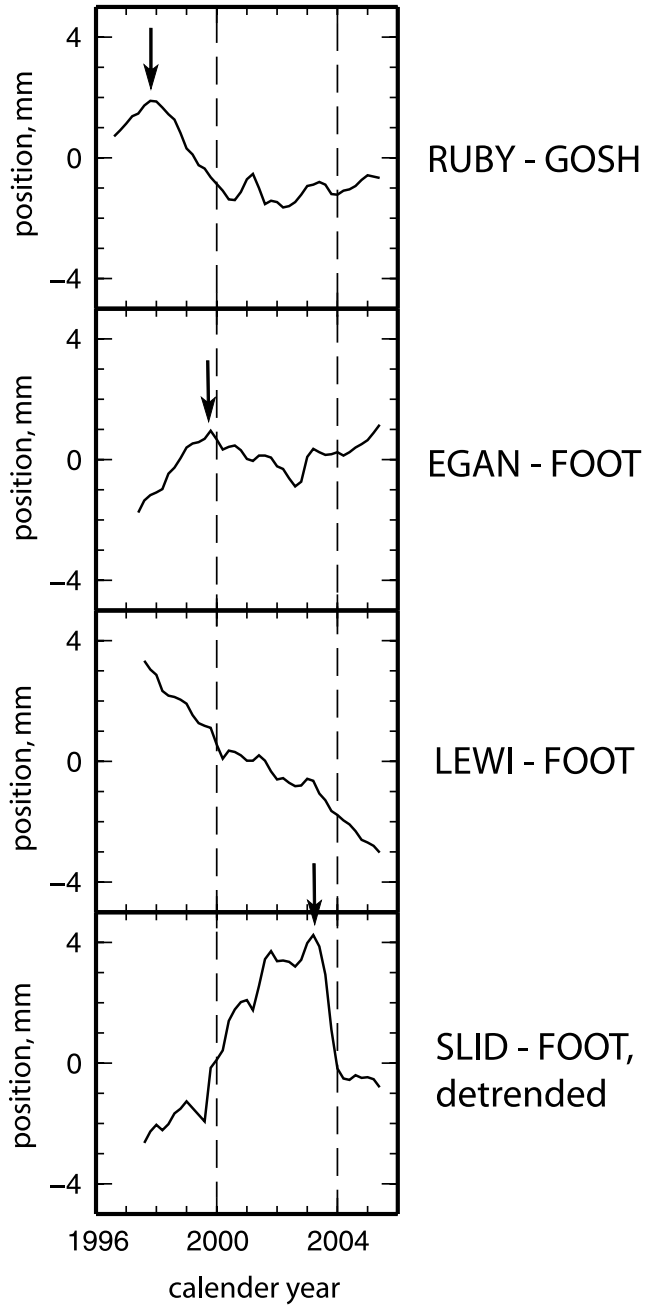

Figure 5. Filtered time series of east component of baseline length for selected sites, using data and methods presented by Davis et al. [2006], except residuals are smoothed with a Gaussian filter with full width at half maximum of $\sim 4$ months instead of $\sim 8$ months; negative slopes in Figures $5 a-5 c$ indicate baseline contraction, positive slopes extension $\left(45^{\circ}=1 \mathrm{~mm} \mathrm{a}^{-1}\right)$. Vertical black arrows show interpreted time of onset of slowing in west velocity. Mean slope of plot in Figure 5d has been removed. Additional baseline length comparisons between pairs of eastern and western domain sites may be found in Figure $3 \mathrm{~b}$ of Davis et al. [2006].

other western domain sites. Because of this motion, its average velocity before 2000 is significantly slower than after 2000. If we interpret RUBY as a western domain site whose eastward motion occurred early and then stopped at about the same time as most of the other sites began to move, then its total eastward position deviation (taking 1998.5 as the cutoff for estimating its early velocity, rather than 2000.0) is $5 \mathrm{~mm}$, similar to other western domain sites (gray arrow, Figure 2b).

[18] As for site LEWI, both its average velocity and the form of its time series differ markedly from most of the other western domain sites, and particularly relative to adjacent sites MINE, ELKO, TUNG and NEWS. Its aver- age velocity is much slower in the east component and has a significant southerly component (Figure 1), and its east time series is one of the most linear of all BARGEN sites (Figure $5 \mathrm{c}$ ). Rather than exhibiting motion leading to extension alternating with shortening as observed for baselines RUBY-GOSH and EGAN-FOOT (Figures 5a and 5b), LEWI has moved steadily toward the western Utah sites at about $1 \mathrm{~mm} \mathrm{a}^{-1}$ for the entire decade of observation (Figure 5c). Its low average velocity has previously been interpreted as either residual motion from stress diffusion after the 1915 M7.6 Pleasant Valley earthquake [Wernicke et al., 2000; Hetland and Hager, 2003], or as an effect of periodic groundwater withdrawal from mining operations in the area [Gourmelen et al., 2007], which we analyze further in section 3.4.

[19] In terms of the end of slowing, we note that site EGAN's motion returns to its pre-2000 average velocity by 2004.5, as is evident from its baseline length plot with site FOOT (Figures $5 \mathrm{~b}$ and $12 \mathrm{a}$ ). This is about 1 year earlier than the average of the western domain sites (Figure 3).

\subsection{Deep Crustal Seismicity in the Tahoe Region}

[20] The primary evidence favoring a tectonic origin for these velocity changes, which also signals its depth of origin in the lithosphere, arises from a temporal correlation between seismicity and geodetic data along the western margin of the province near site SLID beginning in August 2003. Unlike the other western domain sites, SLID's position did not deviate through most of the time period of observation, following the same pattern as the Utah sites. But from August 2003 to February 2004, it moved northeast-and-up at $20 \mathrm{~mm} \mathrm{a}^{-1}$ relative to surrounding sites [Smith et al., 2004], such that its position deviation became similar to that of the other western domain sites (Figure 5d) [Davis et al., 2006]. SLID's strong transient acceleration is temporally and spatially correlated with an unusual swarm of lower crustal earthquakes (29 to $33 \mathrm{~km}$ focal depths, with the largest events M2.5), and an increase in the rate of seismic moment release in the upper crust. The earthquakes in the lower crust were primarily small thrust faulting events, with foci propagating upward along a $\sim 25 \mathrm{~km}^{2}$ plane dipping $50^{\circ}$ ENE [Smith et al., 2004]. The upper crustal pattern of seismicity was primarily via small normal and strike-slip events, in accord with the pattern of faulting in the upper crust. On the basis of the outward motion of SLID in a direction normal to the plane of the swarm and seismic characteristics of the event population, the data strongly suggest active injection of magma into the lowermost crust (Figure 6) [Smith et al., 2004]. The association of the deep seismicity with eastward transient acceleration of SLID implies a lower crustal origin for similar motions across the whole region, which were particularly coherent in 2003 during the injection event (Figure 2c) [see also Davis et al., 2006, Figure 4].

\subsection{Seismic Imaging of the Crust and Uppermost Mantle}

[21] Two major active source seismic imaging experiments of the crust and upper mantle were conducted in the northern Great Basin near latitude $40^{\circ} \mathrm{N}$ during the $1980 \mathrm{~s}$ (Figure 2a), the first a near-vertical incidence reflection profile spanning the province (COCORP $40^{\circ} \mathrm{N}$ profile) 
a)

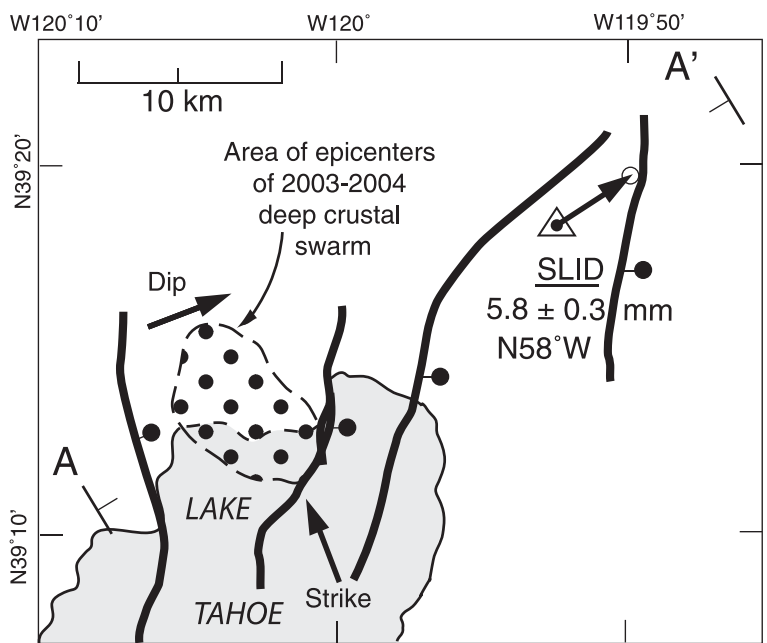

Figure 6. (a) Map showing relationship between the epicentral area of the August 2003 to February 2002 deep crustal seismic swarm and horizontal component of transient motion of site SLID [Smith et al., 2004]. Heavy lines show surface traces of principal normal faults along cross section A-A', ball-and-bar symbol indicates downthrown side. (b) Cross section showing the magmatic injection plane inferred from the seismic swarm in relation to the total (horizontal and vertical) transient motion of site SLID (data from Smith et al. [2004]). Stress state in upper crust as inferred by normal faulting.

[Klemperer et al., 1986; Allmendinger et al., 1987; Hauge et al., 1987; Potter et al., 1987; Hauser et al., 1987], and the second a refraction/wide-angle reflection study coincident with the part of the COCORP profile that covered the western half of Nevada [Holbrook, 1990; Catchings and Mooney, 1991; Holbrook et al., 1991]. A third active

experiment using quarry and mine blast sources was conducted in 2002 by the University of Nevada, which ran SW to NE from the northern Sierra to the western Great Basin [Louie et al., 2004]. A fourth experiment combined active and passive sources to image the crust in northwesternmost Nevada (latitude $41.5^{\circ} \mathrm{N}$ ) in 2004 [Lerch et al., 2007; Gashawbeza et al., 2008].

[22] In Nevada, the COCORP investigation revealed a bright, continuous pair of reflections near Moho depth [Klemperer et al., 1986]. The reflections occur at about $10 \mathrm{~s}$ two-way travel time (TWTT) as separate wavelets about $1 \mathrm{~s}$ TWTT apart, with the upper wavelet " $\mathrm{X}$ " having slightly lower amplitude and less continuity than lower wavelet "M" (Figure 7a). Where compared directly with seismic refraction data the lower wavelet is (within error) at the same depth as the Moho [Holbrook et al., 1991; Catchings and Mooney, 1991]. There is $\pm 1 \mathrm{~s}$ TWTT ( 3 to $4 \mathrm{~km}$ ) of structural relief on these reflections, but there is no systematic change in depth across the province [Klemperer et al., 1986]. Above the Moho to depths as shallow as $4 \mathrm{~s}$ TWTT there is variable development of short, discontinuous reflections, which in some areas are as strong as the Moho reflections [Hauge et al., 1987; Potter et al., 1987], particularly in easternmost Nevada (Figure 7) [Hauser et al., 1987]. At one locality along the Moho, a wide-angle reflection shot gather near BARGEN site TUNG (Figure 2a) exhibited a high-amplitude reflection "bright spot" with a strong $\mathrm{P}$ to $\mathrm{S}$ conversion, interpreted to indicate the presence of a subhorizontal, tabular magma body about $200 \mathrm{~m}$ thick [Jarchow et al., 1993].

[23] Strong Moho reflections are only locally imaged in the Utah Basin and Range, and then only as a single reflection wavelet rather than the pair characteristic of Nevada [Klemperer et al., 1986]. The subhorizontal reflection fabric characteristic of the deep crust in Nevada does not persist into western Utah, where the deep crust is either relatively unreflective or exhibits a west dipping fabric (Figure 7a) [Allmendinger et al., 1987; Hauser et al., 1987]. Because the data from the Utah reflection lines are generally noisier due to cultural activity, the change in structure may be due to greater difficulty in imaging it [Klemperer et al., 1986]. However, the reflection profile across the Nevada-Utah border (COCORP Nevada line 5, Figures $2 \mathrm{a}$ and $7 \mathrm{a}$ ) images a transition zone where short, discontinuous reflections between 5 and $10 \mathrm{~s}$ TWTT overlap with weaker, west dipping reflections characterizing much of west central Utah (reflections G, Figure 7a) [Hauser et al., 1987]. According to amplitude decay profiles [see Hauser et al., 1987, Figure 5], this transition does not appear to be the result of increased noise levels to the east, and the west dipping reflections are clear toward the east, where the subhorizontal fabric is absent.

[24] Nevada line 5 runs directly between BARGEN sites EGAN and FOOT (Figure 2a). In the transition region between reflection characteristics, well developed $M$ and $\mathrm{X}$ reflections and a particularly bright set of deep crustal subhorizontal reflections above $\mathrm{X}$ abruptly terminate, along the downward projection of midcrustal reflections from a major Basin and Range fault (reflection F, Schell Creek fault, Figure 7a). The termination of the $\mathrm{X}$ and $\mathrm{M}$ reflections on this profile occurs about $10 \mathrm{~km}$ west of site FOOT. Hauser et al. [1987] interpreted the zone of midcrustal 

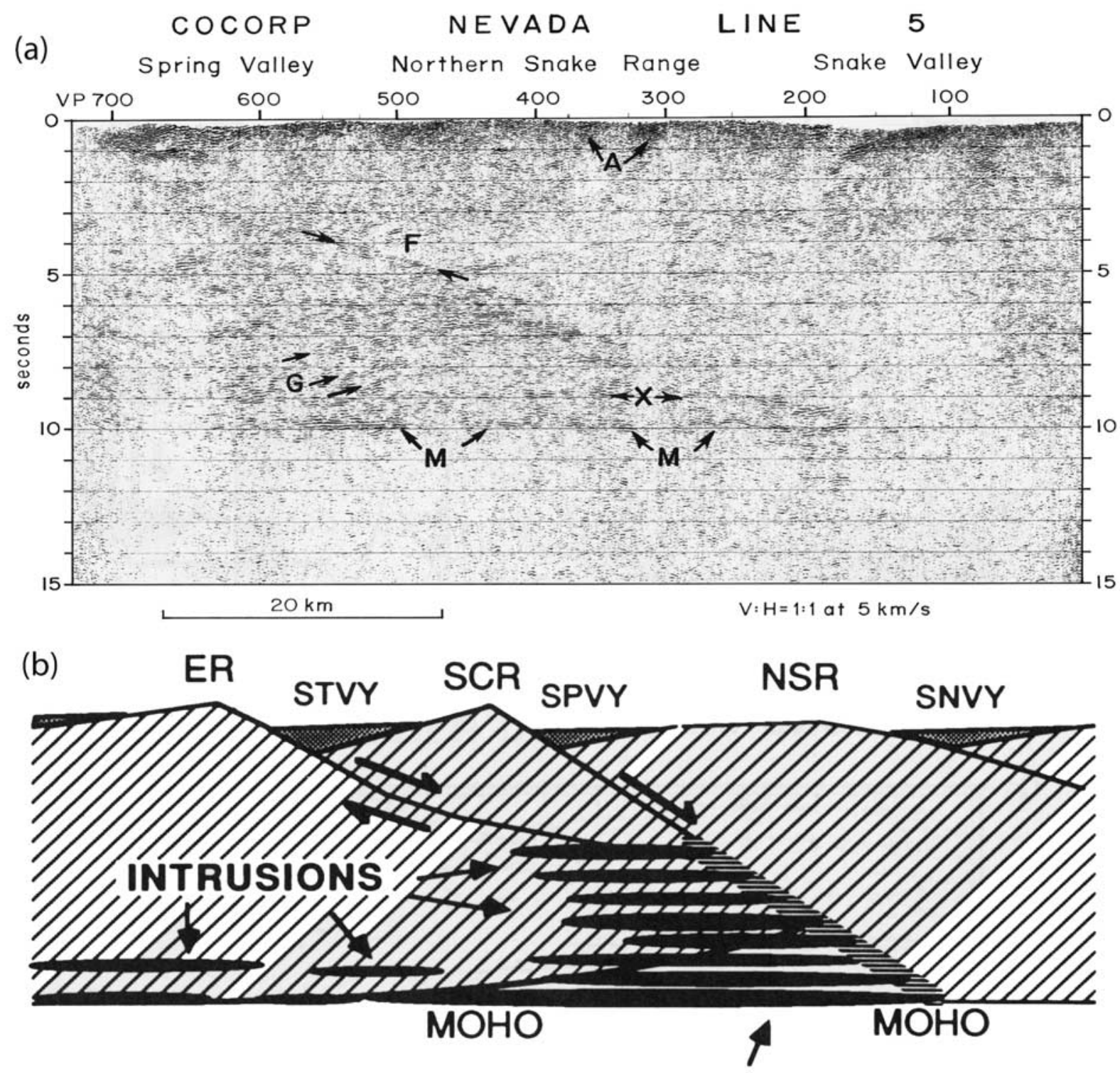

\section{UNDERPLATED MAGMA}

Figure 7. (a) Seismic reflection profile (COCORP Nevada line 5) showing transition between strong Moho reflections (labeled $\mathrm{X}$ and $\mathrm{M}$ ) and subhorizontal deep reflections (unlabeled reflections above $\mathrm{X}$ and $\mathrm{M}$ ) characteristic of Nevada, and the west dipping reflections (labeled G) and weak or absent Moho reflection characteristic of western Utah. East dipping reflections labeled F project upward to the surface trace of the Schell Creek fault just west of VP 700, and downward along terminations of subhorizontal deep crustal reflections. From Hauser et al. [1987]. (b) Schematic east-west cross section showing interpretation of the Schell Creek fault as an active crustal-penetrating boundary against which deep crustal magmatic sills terminate. SNVY, Snake Valley; SPVY, Spring Valley; SCR, Schell Creek Range; STVY, Steptoe Valley; ER, Egan Range. From Hauser et al. [1987].

horizontal reflections as resulting from magmatic injection above a concentrated zone of upwelling in the mantle (Figure 7b), with the Nevada Moho

"perhaps acting as a basal crust detachment for westward translation and extension of the Basin-Range crust relative to the Colorado Plateau. Such decoupling would be enhanced by the development of a lubricating zone of underplated magma."
[25] However one may interpret the reflection patterns, they signal a transition in the structure of the deep crust and uppermost mantle that is spatially coincident with the transition in geodetic behavior from the western domain to the eastern domain.

[26] According to the surveys along the western side of the BARGEN profile, the Moho is between 30 and $35 \mathrm{~km}$ 
depth (although the Louie et al. [2004] survey suggested local variation well outside this range), the seismic velocity ranges from 6.8 to $7.4 \mathrm{~km} \mathrm{~s}^{-1}$ near the base of the crust and is consistently 7.9 to $8.0 \mathrm{~km} \mathrm{~s}^{-1}$ in the upper mantle [Catchings and Mooney, 1991; Holbrook, 1990; Holbrook et al., 1991; Lerch et al., 2007; Gashawbeza et al., 2008]. These velocities suggest on average a mafic composition for the lowermost crust, and an upper mantle that is not abnormally slow. The transition from crust to mantle in Nevada is probably gradational, and the large reflection impedance contrasts are interpreted by most authors to result from active shearing between crust and mantle, cumulate layering in mafic igneous bodies ponded near the Moho, or injection of mafic intrusions into ultramafic upper mantle [e.g., Klemperer et al., 1986; Hauser et al., 1987; Thompson et al., 1989; Holbrook et al., 1991; Lerch et al., 2007; Gashawbeza et al., 2008].

\subsection{Lithospheric Structure, Thickness, and Composition}

\subsubsection{Xenoliths}

[27] Xenoliths are thus far not known from late Cenozoic basalts within the immediate vicinity of the seismic and geodetic survey areas, but do occur to the south in basalts from the Owens Valley area in eastern California [Ducea and Saleeby, 1996], about $220 \mathrm{~km}$ south of site NEWS, and from the Lunar Craters volcanic field in central Nevada [Bergman, 1982], about $120 \mathrm{~km}$ southwest of site EGAN (Figure 1). These xenolith suites are dominated by mafic and ultramafic samples, including cumulate gabbros and dunites presumably from the base of the crust, and spinelbearing peridotites from the upper mantle.

[28] Temperatures at Moho depth beneath the Basin and Range are at least $800^{\circ} \mathrm{C}$, and locally as high as $1300^{\circ} \mathrm{C}$, both on the basis of high heat flux [e.g., Lachenbruch and Sass, 1978] and thermometry of xenolith suites [e.g., Ducea and Saleeby, 1998; Smith, 2000]. Thermobarometry from the Owens Valley suite indicates that the peridotites lie along a melting adiabat from 35 to $70 \mathrm{~km}$ depth, suggesting complete removal of the subcrustal lithosphere from that area. Samples from the Lunar Craters volcanic field include mafic cumulates in equilibrium with host basalt, as well as peridotitic samples derived from the surrounding upper mantle [Bergman, 1982]. Two-pyroxene thermometry from peridotites in this suite record upper mantle temperatures as high as $1285^{\circ} \mathrm{C}$ [Smith, 2000], although the depths of derivation of these peridotites are not known.

\subsubsection{Models of Geodetic and Gravity Data}

[29] Studies of the isostatic rebound of Pleistocene lakes Lahontan and Bonneville (centered on sites UPSA and CEDA, respectively) suggest an 80-km-thick lithosphere with very weak sublithospheric mantle between 80 and $160 \mathrm{~km}$ depth (viscosity $<10^{18} \mathrm{~Pa} \mathrm{~s}$ ), similar to that estimated for the oceanic asthenopshere [Bills et al., 2007]. The weak zone beneath the Lahontan basin appears to be slightly thicker than that beneath the Bonneville basin [Bills et al., 2007], consistent with petrologic data and S tomography that suggest a greater degree of partial melting in the west [Dixon et al., 2004]. These results are consistent with coherence analysis of gravity data suggesting little or no elastic lithosphere in the Great Basin region [Lowry and Smith, 1994].
[30] Models of geodetic displacements after large earthquakes in the southern Great Basin also suggest a weak upper mantle [e.g., Pollitz et al., 2000]. Primarily on the basis of data from a cluster of BARGEN continuous GPS sites in the Yucca Mountain area of southern Nevada [Davis et al., 2003; Wernicke et al., 2004], viscoelastic models of the response of the 1999 Hector Mine earthquake suggest a strong lower crust and uppermost mantle, and a weak upper mantle below $40 \mathrm{~km}$ depth [Freed et al., 2007].

\subsubsection{Seismic Velocities}

[31] One of the earliest seismic studies of upper mantle structure in the region [York and Helmberger, 1973] was based on the delay of long-period $\mathrm{P}$ arrivals from regional earthquakes $\left(10^{\circ}\right.$ to $15^{\circ}$ from source to receiver), and imaged two northeast trending bands of delays, one crossing southern Nevada and terminating near sites FOOT and SMEL, and the other crossing southern Arizona and central New Mexico. The largest delays ( $>5 \mathrm{~s}$ ) were observed beneath sites FOOT and SMEL, in accord with the suggestion by Hauser et al. [1987] of mantle upwelling in the same region, and the eruption of Quaternary basalts at the longitude of site SMEL.

[32] Estimates of the thickness of the "seismic lithosphere" based on shallow incidence teleseismic arrivals in the western Great Basin suggest that it has effectively no thickness [Melbourne and Helmberger, 2001]. Seismic analyses based on steeper incidence P wave arrivals and analysis of gravity data in the southern Great Basin region suggest total lithospheric thickness of 50 to $80 \mathrm{~km}$ [Beghoul et al., 1993; Zandt et al., 1995], consistent with estimates in the same area of 50 to $100 \mathrm{~km}$ (thickening from west to east) based on a petrologic analysis of the depth of melting of late Cenozoic basalts [Wang et al., 2002].

[33] Images of upper mantle structure with high spatial resolution were obtained from a regional tomographic study of $\mathrm{P}$ wave structure, which also suggested strong heterogeneity in velocity [Humphreys and Dueker, 1994a, 1994b; Dueker et al., 2001]. Near the plate boundary a coastparallel, fast/slow anomaly pair is associated with the late Cenozoic subduction system, consistent with the results of Melbourne and Helmberger [2001]. In the plate interior region, the upper mantle is dominated by northeast trending bands of slow and fast $\mathrm{P}$ wave velocity (Figure 8a), in general agreement with the results of York and Helmberger [1973] but differing in some areas as to the location of slow upper mantle. As noted by Humphreys and Dueker [1994b] and Dueker et al. [2001], the northeast trending bands are (1) parallel to the overall Precambrian structural grain and (2) roughly aligned with three northeast trending zones of late Miocene to Recent (5 to $0 \mathrm{Ma}$ ) basaltic volcanism, including (from southeast to northwest) the Jemez, St. George (Utah), and Yellowstone trends (Figure 8a).

[34] In further support of upper mantle heterogeneity, more detailed tomographic models of the southern Sierran region, in concert with xenolith studies, suggest active downwelling of mantle lithosphere beneath the southern part of the Great Valley, with consequent removal of nearly all subcrustal lithosphere beneath the southeastern Sierra Nevada and adjacent Basin and Range [Ducea and Saleeby, 1996; Park et al., 1996; Zandt et al., 2004; Saleeby and Foster, 2004; Le Pourhiet et al., 2006]. A densely sampled passive experiment from the central Colorado Plateau to the 
(a)

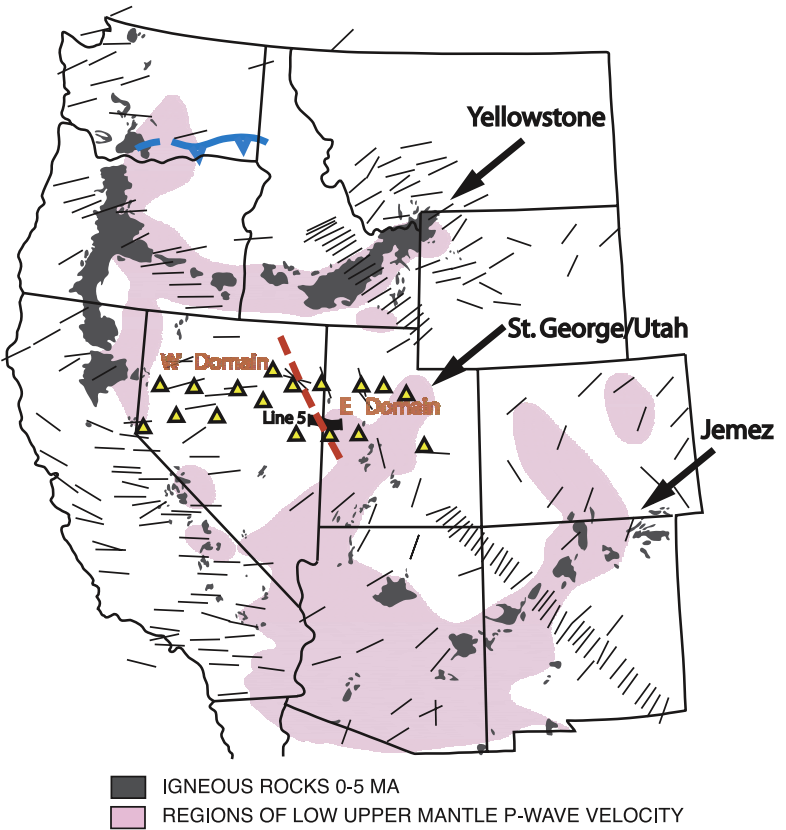

(b)

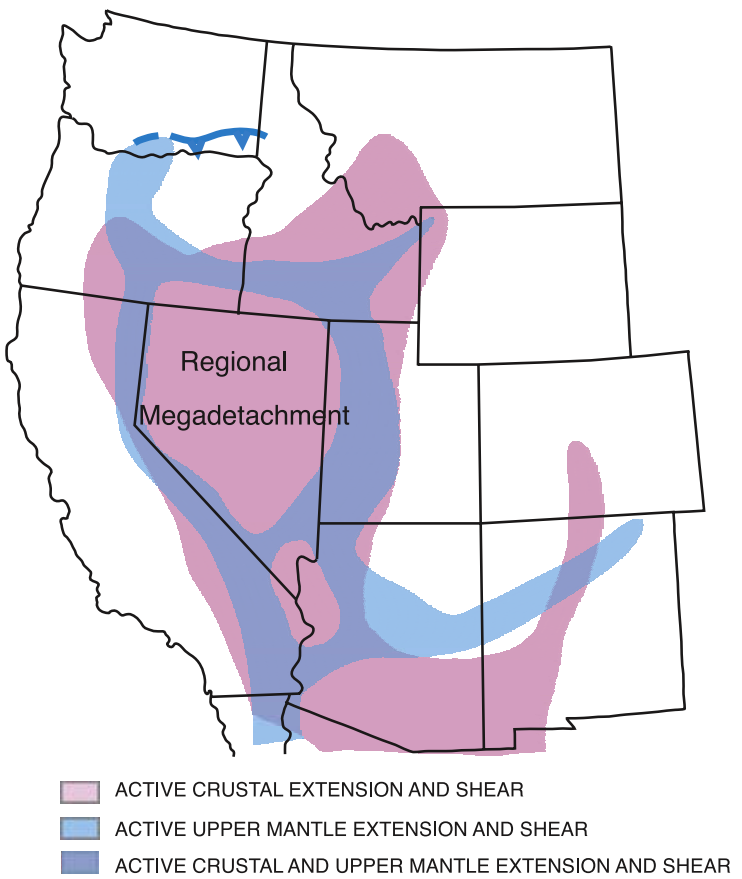

Figure 8. (a) Map showing BARGEN sites from Figure 2 (triangles), the distribution of volcanic rocks younger than $5 \mathrm{Ma}$ (black) after Luedke and Smith [1984], areas of slow P wave velocity $(<\sim 1 \%$ average) at $100 \mathrm{~km}$ depth (pink) after Dueker et al. [2001] and Humphreys and Dueker [1994a], and orientations of fast $\mathrm{S}$ direction (thin black lines; magnitude not indicated) after Savage and Sheehan [2000]; lack of orientation data in east central Nevada reflects isotropy. (b) Map showing the distribution of late Cenozoic upper crustal extension compared with the distribution of extension of the subcrustal lithosphere inferred from magmatism and slow $\mathrm{P}$ wave velocity.
Great Plains (LA RISTRA) [Wilson et al., 2005] imaged a broad low in $\mathrm{S}$ wave velocity in the upper mantle centered on the Jemez trend and Rio Grand Rift (Figure 8a). Synthesis of the seismic, gravity and xenolith data along the Jemez trend and environs suggests it is underlain by a broad region of buoyant upper mantle created through some combination of metasomatism, extensional upwelling and partial melting relative to surrounding areas, in a pattern discordant to the present-day trend of the Rio Grande rift [Roy et al., 2005].

\subsubsection{Shear Wave Splitting}

[35] Polarization ("splitting") of shear waves due to velocity anisotropy is interpreted to result from some combination of lithospheric structure and sublithospheric mantle flow [Silver, 1996], with the fast direction indicating the direction (but not sense) of asthenospheric shear. The predominant direction of fast $\mathrm{S}$ wave velocity in southwestern North America is NE [Savage and Sheehan, 2000], perpendicular to the plate boundary and parallel to interior $\mathrm{P}$ wave slow anomalies, late Cenozoic magmatic belts and the Precambrian structural grain (Figure 8a). Two exceptions to the overall northeast trend include (1) clockwise rotation as one approaches the plate boundary, to an overall E-W to W-NW trend, and (2) a strikingly isotropic region in east central Nevada and west central Utah, surrounded by an intriguing semicircular pattern of fast $\mathrm{S}$ velocity directions (Figure 8a). The semicircle forms a convex east arc from northern Nevada, across western Utah, and then back into southern Nevada, with the center of the arc located roughly halfway between BARGEN sites NEWS and EGAN [Savage and Sheehan, 2000].

[36] Comparison of the average GPS velocity field with the pattern of fast directions over the thinnest western U.S. lithosphere (nearest the plate boundary to the west) suggests that the sublithospheric mantle is flowing at about $5 \mathrm{~cm} \mathrm{a}^{-1}$ due east [Silver and Holt, 2002] in a Pacific hot spot reference frame [Gripp and Gordon, 1990]. This analysis excludes from consideration the semicircular arc over the Great Basin on the grounds that it may be contaminated by lithospheric structure, and emphasizes instead a relationship between the GPS velocity field and the clockwise rotation of the fast directions toward the plate boundary. Assuming the fast directions in the arc do correspond to the direction of horizontal shear within the asthenosphere, it may be interpreted as parabolic flow via the entrainment of a mantle plume head into the southwestward motion of the North American plate [Savage and Sheehan, 2000]. Using the better constrained Pacific hot spot reference frame of Gripp and Gordon [2002], Walker et al. [2004] calculate an azimuth of shear between North America and the hot spot frame of $251 \pm 21^{\circ}$. In both models, a top-to-the-southwest shear traction on the upper mantle opposes the motion of the plate relative to the hot spot frame. In a third explanation of the splitting directions, the arc beneath the Great Basin may represent the surface projection of a toroidal pattern of asthenospheric return flow (counterclockwise in map view) [e.g., Schellart et al., 2007] around the foundering southern edge of the Gorda-Juan de Fuca plate [Zandt and Humphreys, 2008]. This model implies top-to-the-south to top-to-the-east tractions between North American lithosphere and asthenosphere, depending on position within the arcuate pattern of fast directions. 

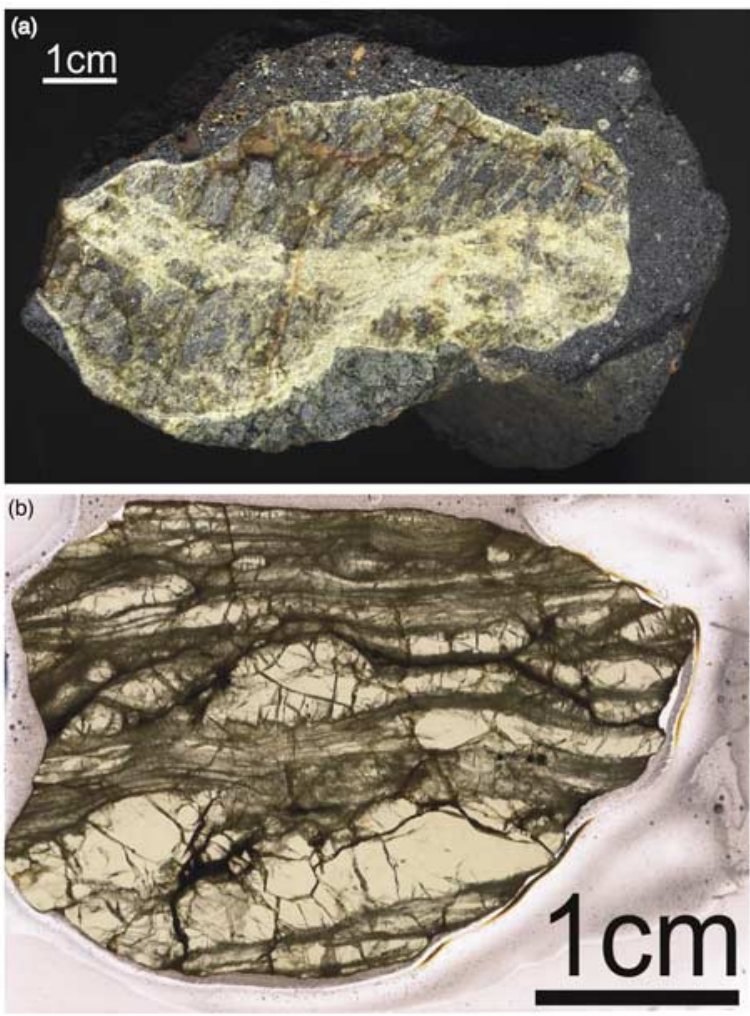

Figure 9. Representative deformation textures in dunite xenoliths from the Marcath cinder cone, Lunar Craters volcanic field, Nevada (Figure 1); both samples contain $2 \mathrm{ppm}$ weight percent $\mathrm{H}_{2} \mathrm{O}$ in olivine (Table 1). (a) Photograph of polished surface of sheared dunite xenolith showing strong grain size reduction of olivine megacrysts, sample ME02. (b) Photomicrograph (plain light) of dunite mylonite showing strong foliation defined by fine-grained, localized shear zones and coarse, sheared olivine porphyroclasts, sample MS001.

[37] In summary, a diverse set of proxies for upper mantle structure are in broad agreement that beneath the interior of the western U.S. the lower crust is relatively strong, the subcrustal lithosphere thin ( $\sim 0$ to $50 \mathrm{~km})$, and the asthenospheric mantle weak. Tomographic and petrologic data are consistent with significant variation in the thickness of subcrustal lithosphere, with the strongest evidence for little or no subcrustal lithosphere beneath the Owens Valley area and perhaps west central Utah. The predominant trend of (1) Proterozoic structures, (2) late Cenozoic magmatic belts, (3) P wave velocity variations and (4) the fast direction of $\mathrm{S}$ wave polarization is NE, perpendicular to the plate boundary (Figure 8a). Shear wave splitting data has been interpreted to reflect either top-to-the-southwest shear or an arcuate pattern of top-to-the-south to top-to-the-east tractions between the lithosphere and the asthenosphere in the region of the BARGEN array. In the near future these conclusions will be robustly tested by the USArray component of the EarthScope program.

\subsection{Hydrolytic Weakening of Great Basin Upper Mantle?}

[38] Unusually thin continental lithosphere and weak upper mantle raises the possibility that hydrolytic weaken- ing derived from volatile fluxing during Laramide flat slab subduction [Humphreys et al., 2003] is an important contributor [Dixon et al., 2004]. If olivine contains trace amounts of water (in the range 50 to $250 \mathrm{ppm}$ by weight), then its strength can be reduced by more than 2 orders of magnitude [Hirth and Kohlstedt, 1996]. Xenolith suites from mid-Tertiary basalts on the Colorado Plateau commonly contain hydrous phases and other evidence of fluid interaction [Usui et al., 2003; Smith et al., 1999; Lee, 2005], consistent with this hypothesis. However, although a volumetrically minor component of the Lunar Craters xenolith suite contains amphibole-bearing mafic veins [Bergman et al., 1981], xenoliths from this area and elsewhere in Basin and Range province do not commonly contain hydrous minerals. The presence of accessory hydrous phases clearly indicates fluid infiltration but does not constrain the extent and rheological consequences of this process. However, water content in olivine appears to be a reliable indicator of hydration-induced weakening.

[39] Included in the Lunar Craters suite are strongly foliated, fine-grained mylonitic dunites and subordinate wehrlites, with olivine grain size in shear zones reduced to 10 to $150 \mu \mathrm{m}$ [Bergman, 1982]. Although there are no reliable independent geothermometric constraints on equilibrium temperatures of these samples, the relatively small grain size, strong foliation, and preservation of undulatory extinction in olivine are consistent with high-stress, grain size sensitive creep that occurs in the low-temperature range of crystal plastic flow of olivine between $700^{\circ} \mathrm{C}$ and $1000^{\circ} \mathrm{C}$ (Figure 9) [Bergman, 1982; Passchier and Trouw, 2005]. In contrast, the hotter (and presumably deeper) harzburgites from the same suite are essentially undeformed. Assuming the rocks are dry, altogether these observations suggest a relatively strong lithospheric mantle in which deformation was focused to its shallowest and compositionally most distinct levels, presumably near the base of the crust where seismic refraction data suggest ponding of mafic magmas.

[40] To test for the possibility of hydrolytic weakening in these rocks, we conducted a reconnaissance study of water content in olivine from a variety of xenoliths in the Great Basin region using Fourier transform infrared spectroscopy [Bell and Rossman, 1992], including samples from the Lunar Craters, the Dish Hill basalt in the central Mojave Desert, and the Waucoba basalts from the Owens Valley area (denoted L, D, and W, respectively on Figure 1).

[41] Most relevant to our geodetic transect are nine ultramafic xenolith samples from the Lunar Craters volcanic field (Table 1). All of the samples were collected from the late Quaternary Marcath cinder cone and flow near the northern end of the volcanic field, which is particularly rich in ultramafic xenoliths. Xenoliths with the compositions of our sample suite are not in $\mathrm{Sr}$ isotopic equilibrium with the host magma, and are thus representative of upper mantle or lower crustal wall rocks encountered by the magma during ascent [Bergman, 1982]. Of these samples, two harzburgitehosted olivines contain 14 to $15 \mathrm{ppm}$ water by weight and the remainder less than $5 \mathrm{ppm}$ each. These are considered well below levels that would have any weakening effect [Hirth and Kohlstedt, 1996]. In particular, sheared dunite xenoliths (Figure 9) had very low dissolved water content. Measurements of water content similar to these were also 
Table 1. Water Content of Olivines in Xenoliths From Marcath Cone and Flow (centered at latitude $38^{\circ} 29^{\prime} 18^{\prime \prime} \mathrm{N}$ and longitude $\left.115^{\circ} 59^{\prime} 13^{\prime \prime} \mathrm{W}\right)$, Lunar Craters Volcanic Field, Nevada

\begin{tabular}{lcc}
\hline Sample & Petrography & $\mathrm{H}_{2} \mathrm{O}$ in Olivine \\
\hline ME01A & spinel harzburgite & 5 \\
ME02 & sheared dunite & 2 \\
ME03 & spinel harzburgite & 15 \\
ME04 & spinel harzburgite & 14 \\
ME06 & dunite & 3 \\
ME07 & dunite & 2 \\
MFE3 & spinel wehrlite & 2 \\
MS001 & mylonitic dunite & 2 \\
MS01 & spinel harzburgite & 4 \\
\hline
\end{tabular}

${ }^{\text {a }}$ Expressed as ppm by weight; accumulated uncertainties are $5 \mathrm{ppm}$ at the $15 \mathrm{ppm}$ level, and $1 \mathrm{ppm}$ at the $2 \mathrm{ppm}$ level.

obtained on xenoliths from the Waucoba and Dish Hill basalts (P. Luffi, unpublished data, 2007).

[42] The eruption of xenoliths may cause significant water loss from olivine [Demouchy et al., 2006], and therefore our measurements may underestimate the hydration state of these samples. However, the lattice-preferred orientation of olivine from the Lunar Crater mylonitic dunites is consistent with deformation in a low-hydration regime ( $<10$ ppm water) [Katayama et al., 2004] and thus the measured water contents are probably not far from the preeruption conditions. A more comprehensive study of the xenolith chemistry and microstructure bearing on the question of stress levels and deformation mechanisms is needed, but existing information points toward at least local maintenance of high shear stresses in a dry, strong deep crust and uppermost mantle, despite relatively thin lithosphere and weak sublithospheric mantle.

[43] Because the sampling density of the xenolith suites is quite sparse, and they may preferentially occur in areas where the mantle lithosphere has been greatly thinned or removed by small-scale convection or other processes, these data do not rule out preservation of large areas of weak, hydrous upper mantle under the Great Basin region. To the extent that the upper mantle in the Great Basin region has been "wrung out" by the production of upper Eocene to middle Miocene andesites and basalts [Dixon et al., 2004], one can envisage a period of time after the Laramide when the crust was thick and the upper mantle was hydrous and weak, whereas following mid-Tertiary magmatism, extension and convective loss, the lithosphere became thinner and the upper mantle cooler, dryer and therefore much stronger. We note in particular that data from the xenolith suites suggesting strong uppermost mantle are consistent with studies of postseismic deformation patterns that indicate a strong lithosphere down to at least $40 \mathrm{~km}$ depth [Freed et al., 2007].

\section{Synthesis}

\subsection{The Case for a Megadetachment}

[44] The temporal and spatial coherence of the geodetic velocity change, the link between SLID's velocity change and magma injection at Moho depth, the strong reflectivity and "bright spots" at the base of the crust, and the presence of mylonitic cumulate dunites in xenoliths all point toward active intrusion and shearing on or near the Nevada Moho, with the crust shearing unidirectionally relative to the upper mantle. But what is the sense of shear? Given that the duration of the slowing event is more than half the observation period, this hypothesis immediately raises the question as to whether the 1999.5 velocity change represents the beginning or the end of a strain release event. If the slower velocities represent release, then the direction of active shear is top-to-the-east (Figure 10a). If, however, faster west velocity represents release, then the direction of shear is top-to-the-west (Figure 10b), consistent with the direction suggested by Hauser et al. [1987] discussed in section 2.5.

[45] Three independent lines of evidence suggest that slowing represents release (1) comparison of the strain pattern with those associated with slow slip events (SSEs) on subduction megathrusts, the closest analog in tectonic geodesy with which we can make an empirical comparison; (2) the association of the eastward motion of site SLID with magma injection; and (3) the state of stress at Moho depth indicated by the magma injection event.

[46] Despite their radically different tectonic settings, drawing as close an analogy as possible between the Great Basin geodetic data and subduction zone transients provides a satisfactory explanation for the otherwise puzzling alternation between extension and contraction along the boundary between the eastern and western domains (Figures $5 \mathrm{~b}$ and 10). In such an analogy (Figure 11), the Basin and Range mantle would either translate or stretch smoothly below the detachment, imparting top-to-the-east shear traction on the base of the crust (Figure 11, middle). While the megadetachment is "locked" (or, possibly slipping in a steady state mode), horizontal extensional strain accumulates in the hanging wall, opposite to the horizontal contraction observed above a locked subduction zone. When the detachment yields, westward motion of the upper plate slows as strain energy is released (Figure 11, bottom). In this phase, the entire western Basin and Range crust is shuttled eastward, analogous to the motion of the inner forearc region during SSEs, except that western sites do not completely change direction relative to the continental interior, as occurs in the Cascadia SSEs. During the shuttling process, hyperextension and magmatism (anelastic strain release) along the western margin of the block is balanced by shortening (elastic strain release) along the eastern margin (Figure 10a).

[47] The distribution of crustal strain through this cycle is clearly a complex problem. We suggest in Figure 11 that strain is distributed during accumulation and more focused during release. The velocity field suggests the accumulation of elastic strain occurs primarily in western Nevada (Figure 2a). In contrast, elastic release seems to be focused in eastern Nevada, because there are no large, systematic differences in position deviation between EGAN and SLID (Figure 2b). Hence the system exhibits behavior significantly more complex than the traditional concept of a seismic cycle, where elastic accumulation and release are cospatial.

[48] The duration of eastward relative displacement of site SLID is much shorter than the other sites (except as noted above, site RUBY in late 1998), and its association with magma injection also clearly reflects strain release (Figure 6). The injection event near the base of the crust 
a)

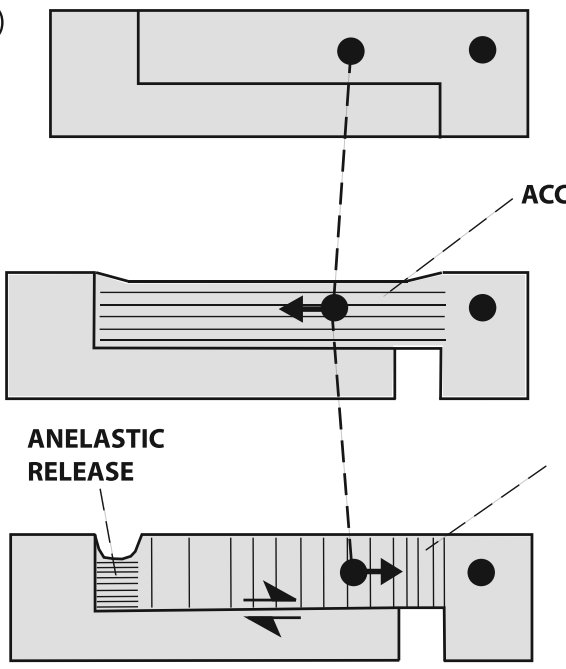

TOP - EAST SHEAR

(Release corresponds to slower west velocity)

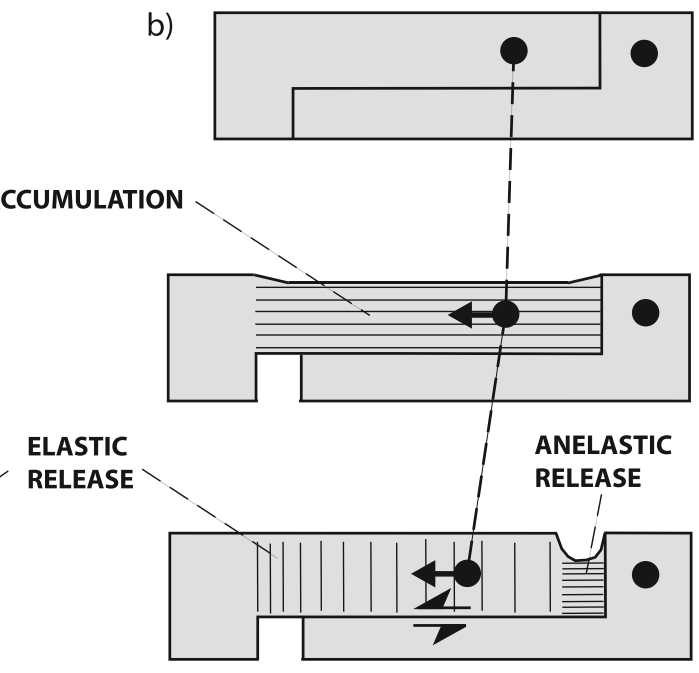

TOP - WEST SHEAR

(Release corresponds to slower east velocity)

Figure 10. Schematic east-west cross-sectional models (not to scale) illustrating two possible strain release modes for the megadetachment discussed in text. (a) Strain release top-to-the-east, implying faulting in western Nevada is transferred to subcrustal lithospheric extension in west central Utah; (b) strain release top-to-the-west, implying the opposite sense of strain transfer than in Figure 10a. Black lines indicate direction of maximum elongation direction, with strain roughly proportional to spacing.

involved $\sim 1 \mathrm{~m}$ of displacement, and occurred simultaneously with a pulse of local extensional strain release via upper crustal small earthquakes [Smith et al., 2004] and regionally coherent, rapid deceleration of all of the other sites in the network, except for the easternmost sites (compare Figure 2c with Figure $4 \mathrm{~b}$ of Davis et al. [2006]).

[49] The geometry of magmatic injection along an ENE dipping plane provides a third important constraint on the

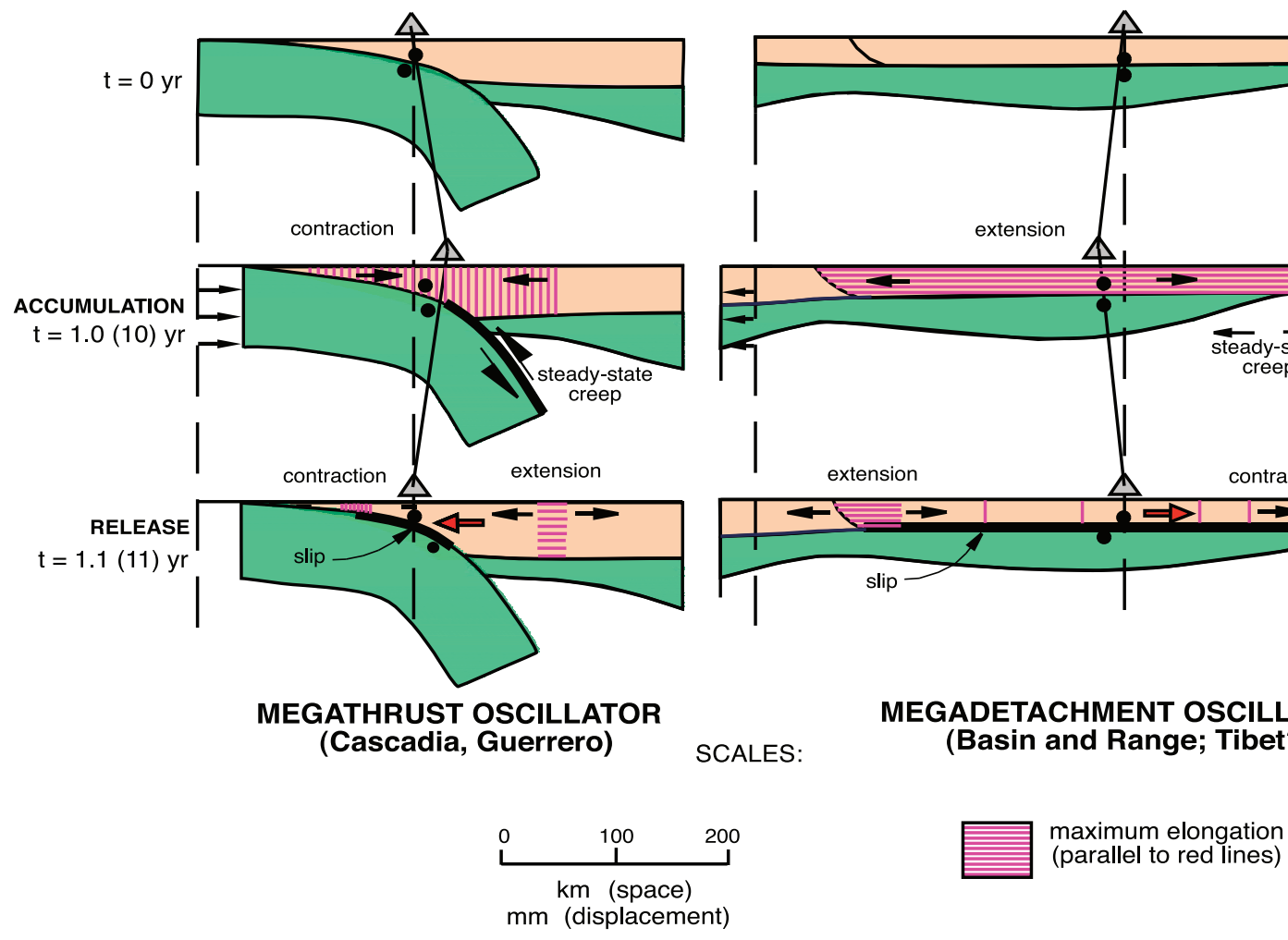

Figure 11. Schematic cross-sectional models drawing analogy between top-to-the-east displacement and associated strain patterns on the megadetachment and slow earthquakes in a subduction zone setting as described in text. 
(a)

(b)

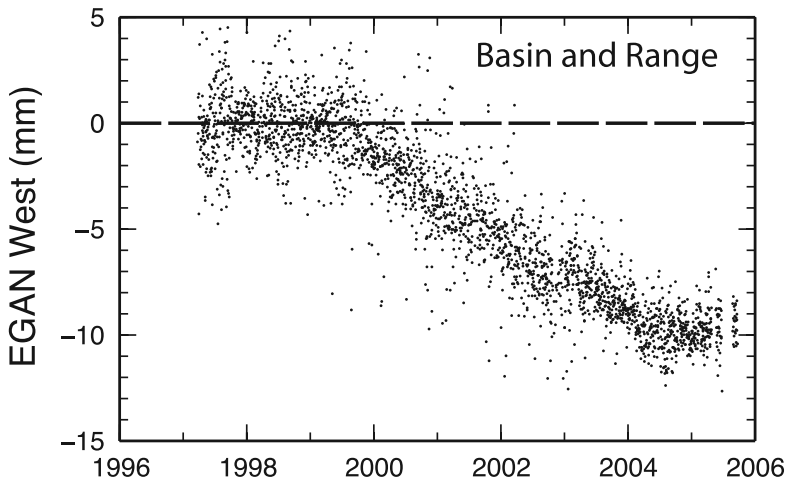

(c)

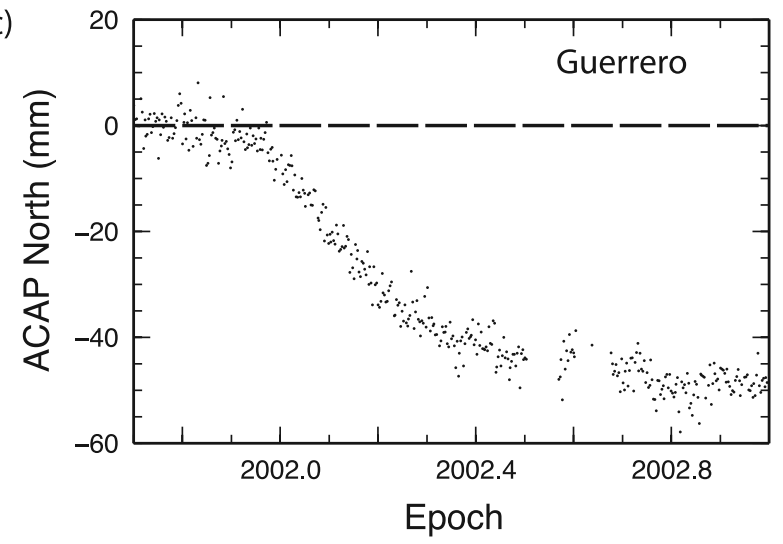

Figure 12. Filtered, detrended time series for (a) east component of baseline EGAN-FOOT, (b) longitude of Cascadia site KTBW during the early 2003 slow earthquake [Melbourne et al., 2005], and (c) latitudinal position of site ACAP during Guerrero SSE of 2001-2002 [Kostoglodov et al., 2003]. Reference frame (zero motion) is established by linear regression through the individual time series between the identified strain events (e.g., pre-2000 data for EGANFOOT is assigned zero slope). Note differences in displacements and timescales among the events; see Table 2 for estimates of source parameters. question of strain release. Given the nominal assumption that the injection occurred along a tensile (mode I) fracture, the minimum principal stress direction at the base of the crust is normal to the injection plane, which is well defined by the array of event locations to dip $50^{\circ}$ ENE [Smith et al., 2004]. If the minimum principal stress direction at the base of the crust plunges $40^{\circ} \mathrm{WSW}$, then the maximum shear tractions are subparallel to the Moho with a sense top-tothe-ENE (Figure 6). These data in isolation might only apply to the local state of stress in the lower crust around site SLID, but given the regional coherence of the 2003 displacements, it seems difficult to ascribe a markedly different state of stress during slip along the structural element causing the motion. Any viscous or plastic yielding would therefore be favored along subhorizontal planes, and eastward deviations in site position (slowing west velocity) would represent strain release compatible with this state of stress. The opposite interpretation (i.e., westward deviation or increasing west velocity) would require top-to-the-west shear during strain release (Figure 10b), opposite in sign to the shear tractions indicated by the injection event.

\subsection{Amount of Slip and Energy Release}

[50] From the Great Basin geodetic data, we estimate maximum displacement at the Earth's surface of about $10 \mathrm{~mm}$ (Figure 2b), about a factor of 2 larger than the Cascadia events and about factor of 5 lower than Guerrero SSEs [Miller et al., 2002; Melbourne et al., 2005; Lowry et al., 2001; Kostoglodov et al., 2003]. By comparing the time series for western domain BARGEN sites with those for Cascadia and Guerrero (Figure 12), we observe a wide range of behaviors. Event durations and displacements, as well as estimates of the area of subsurface slip and frequency of occurrence span at least an order of magnitude for these three examples alone (Table 2).

[51] In terms of seismic moment, Melbourne et al. [2005] modeled the slip on the Cascadia subduction interface using a Green's function approach [Okada, 1992]. Assuming slip on a shallowly dipping $\left(10^{\circ}\right.$ to $\left.15^{\circ}\right)$ shear zone, source modeling suggested $4 \mathrm{~cm}$ maximum slip along a $\sim 50-\mathrm{km}$-wide patch from 25 to $40 \mathrm{~km}$ depth, yielding a moment magnitude $\mathrm{M}_{\mathrm{w}}=$ 6.6 (Table 1). The "upward damping" of displacement from source to the Earth's surface in the Cascadia models is 80 to $85 \%$ because of the relatively narrow area of slip, where the depth of the source is about the same as its width. A similar analysis of the Guerrero event of 2001-2002 suggested a maximum slip of $10 \mathrm{~cm}$ on a $550 \times 220 \mathrm{~km}$ plane, yielding a moment magnitude $\mathrm{M}_{\mathrm{w}}=7.5$ (Table 1).

[52] The east-west extent of the Great Basin velocity changes is about $500 \mathrm{~km}$. The north-south extent is uncertain, but many of the BARGEN sites installed in 1999 to 2002 over a region approximately $500 \mathrm{~km}$ to the

Table 2. Comparison of Estimates of Source Parameters and Frequencies of Selected Aseismic Strain Release Events

\begin{tabular}{lcccccc}
\hline \multicolumn{1}{c}{ Event } & $\begin{array}{c}\text { Maximum } \\
\text { Offset }(\mathrm{cm})\end{array}$ & $\begin{array}{c}\text { Area } \\
(\mathrm{km} \times \mathrm{km})\end{array}$ & $\begin{array}{c}\text { Moment } \\
\text { Magnitude }\end{array}$ & $\begin{array}{c}\text { Duration } \\
\text { (years) }\end{array}$ & $\begin{array}{c}\text { Frequency } \\
\text { (years) }\end{array}$ & Reference $^{\mathrm{a}}$ \\
\hline Cascadia 2003 & 4 & $50 \times 300$ & 6.6 & 0.1 & 1 & 1 \\
Guerrero 2001-2002 & 10 & $220 \times 550$ & 7.5 & 0.7 & 6 & 2 \\
Great Basin 2000-2004 & 1 & $500 \times 500$ & 7.2 & 6 & $>10$ & 3 \\
\hline
\end{tabular}

${ }^{a}$ References: 1, Melbourne et al. [2005]; 2, Kostoglodov et al. [2003]; 3, this paper. 


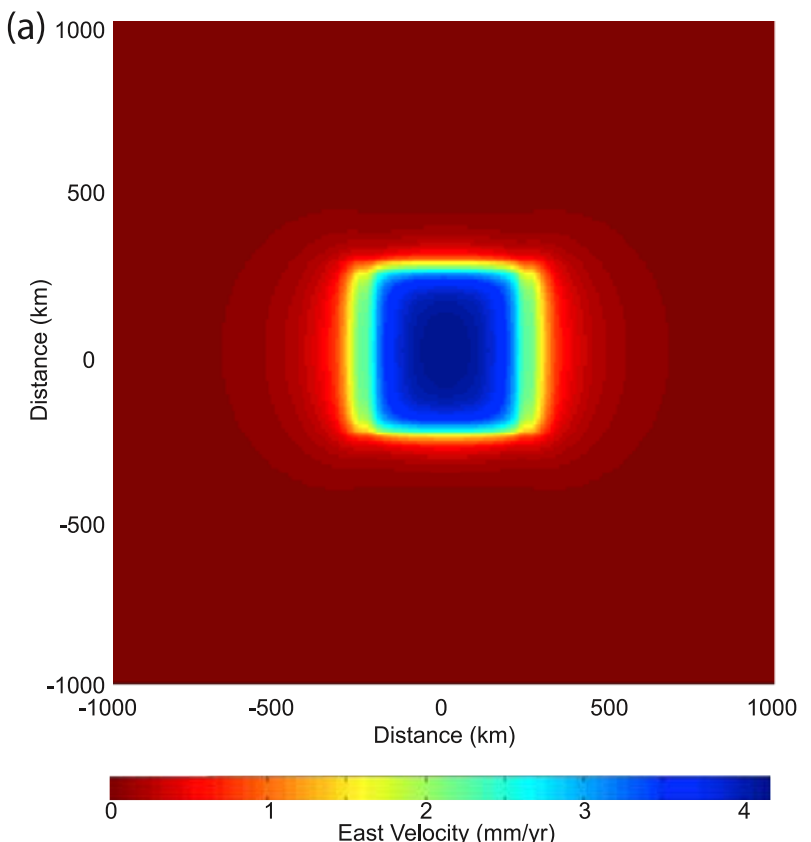

(b)

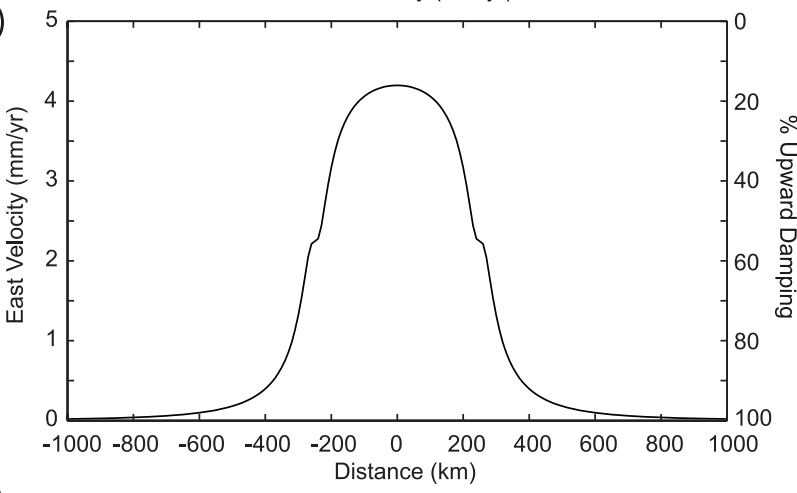

(c)

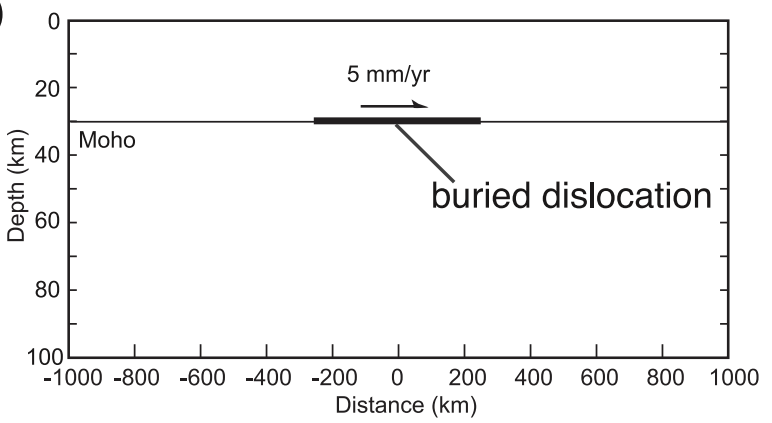

Figure 13. (a) Map of surface horizontal velocity anomaly for $500 \mathrm{~km} \times 500 \mathrm{~km}$ horizontal dislocation buried at a depth of $30 \mathrm{~km}$ slipping uniformly at $5 \mathrm{~mm} \mathrm{a}^{-1}$ due east, using the method of Okada [1992]. (b) Plot showing horizontal velocity anomaly versus position in the direction of slip at midpoint of the model, parameterized as surface velocity (left axis, $\mathrm{mm} \mathrm{a}^{-1}$ ) and upward damping of horizontal velocity (right axis, percent of slip along dislocation). (c) Cross section of dislocation plane (heavy line) and sense of shear (arrow).

south of the transect have exhibited increasing west velocity after 2004.0 (J. L. Davis et al., unpublished data, 2007) and we therefore suspect the structure may have an along-strike dimension of order $500 \mathrm{~km}$ (Table 2). If we assume a
$500 \mathrm{~km} \times 500 \mathrm{~km}$ zone of slip at a depth of $30 \mathrm{~km}$, the depth of the source is an order of magnitude less than its width, and upward damping of displacement is as little as $15 \%$ in the center of the region of slip and no more than $\sim 40 \%$ near the margins (Figure 13). If we assume an average surface slip of $7 \mathrm{~mm}$ and upward damping in the range of $20 \%$ to $50 \%$, then the net slip on the detachment would lie in the 8 to $12 \mathrm{~mm}$ range. Assuming a uniform value of $10 \mathrm{~mm}$ (the midrange between $8 \mathrm{~mm}$ and $12 \mathrm{~mm}$ ) and a rigidity modulus of $75 \mathrm{GPa}$, we obtain a seismic moment of $8 \times 10^{26}$ dyn $\mathrm{cm}$, corresponding to moment magnitude $\mathrm{M}_{\mathrm{w}}=7.2$ (Table 2). If slip only affected the $\sim 150 \mathrm{~km} \mathrm{NS}$ aperture of the network, the moment would be $2.0 \times 10^{26}$ dyn $\mathrm{cm}$, or $\mathrm{M}_{\mathrm{w}}=6.8$. Clearly, this estimate is only certain to within an order of magnitude in moment.

\subsection{Long-Term Pattern of Slip}

[53] If the cycle suggested by time series such as EGANFOOT or the stack in Figure 3 results from $1 \mathrm{~cm}$ of yielding every decade, then the average slip rate on the detachment is $1 \mathrm{~mm} \mathrm{a}^{-1}$, or about a factor of 5 lower that the net difference in the west components of velocity across the block, between sites in western Utah (e.g., FOOT) and eastern California (e.g., SLID), and only $10 \%$ of the difference in total west velocity across the network of $\sim 10 \mathrm{~mm} \mathrm{a}^{-1}$. This raises the question of why the slowing primarily affects the east components of motion. In the western part of the Basin and Range, where the active strain field is NNW right-lateral shear, the direction of both displacement and the velocity anomaly is generally ENE, normal to the N20W shear direction [Bennett et al., 2003], and approximately normal to the transform plate boundary (Figures $2 \mathrm{~b}$ and 2c). Strain release in this region thus seems to reflect some sort of partitioning between margin-normal extension along the Moho, and the net shear accommodated in western Nevada. With only one observed event, it is premature to speculate on how such partitioning might be accomplished. However, it appears that yielding is primarily reflecting the extensional component of the strain.

[54] Assuming the last decade is typical of the longerterm history, either (1) yielding along the detachment is mostly steady state, with only a component of stick-slip superimposed, or (2) the detachment functions as a "transfer" structure with modest net displacement that accommodates differential strain between crust and mantle, such that its net slip need not reflect the total displacement. For the first hypothesis, eastern Nevada could conceivably be rheologically modeled as a slider block along the Moho, recovering most or all of the elastic strain applied along its base (Figure 11). But except for site SLID, strain release of the western Nevada sites was not as rapid as continued accumulation. A simple slider block model thus breaks down in that it would involve the complicating factor of a slider block that internally deforms during sliding. An approach similar to Coulomb wedge theory might be applicable [Davis et al., 1983], but models accounting for both hanging wall deformation and stick-slip constitutive behavior have not been attempted to our knowledge.

[55] The second hypothesis may be attractive given the heterogeneity in structure of the subcrustal lithosphere described above, but the relative simplicity of the overall displacement field during slip militates against it. For 

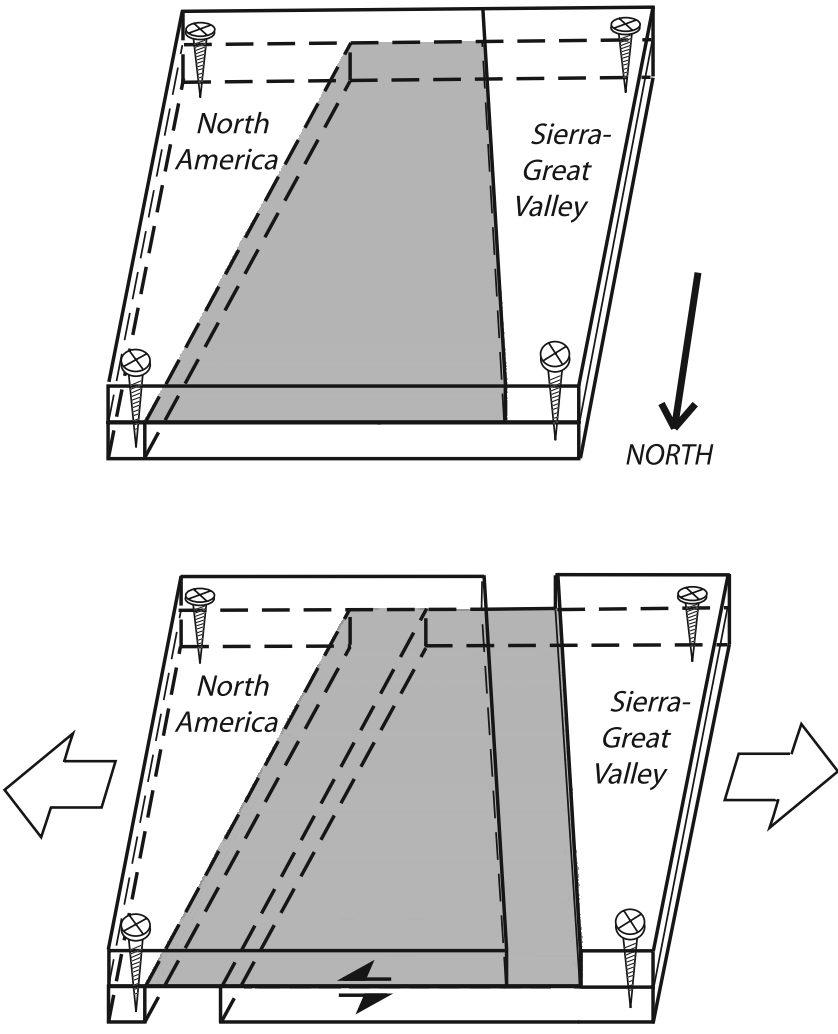

Megadetachment surface

Figure 14. Schematic three-dimensional, strain-compatible model showing the role of the megadetachment in accommodating discordant strain patterns between differently oriented crust and upper mantle extension zones during slip on the detachment. Model neglects strike-slip component of Great Valley-North America motion, which is presumably focused along the right-hand margin of the megadetachment zone (Figure 15). example, for a system with just two zones of localized strain in the upper mantle, transferring extension upward through the lithosphere would generate three domains across which tractions on the base of the crust would change polarity, inconsistent with uniformly eastward slip. For this reason (and following Figure 8a) we depict two zones of localized upper mantle strain on either side of Nevada (Figures 11, 14 , and 15). The zone of very thin lithosphere along the western margin is based on (1) the presence of young basalts in the Tahoe region, including the evidence for magma injection at depth; (2) extrapolation northward from the region of thin lithosphere beneath the Owens Valley area; and (3) the very thin lithosphere along the eastern margin of the northern Sierra imaged by Melbourne and Helmberger [2001]. Thin lithosphere beneath west central Utah is based on (1) the St. George trend of basaltic volcanism, which we interpret to include a north trending belt of young basalts and rhyolites in the vicinity of sites SMEL and FOOT; (2) the slow region in west central Utah imaged by York and Helmberger [1973] beneath sites FOOT and SMEL; and (3) the inferred source region for basaltic injection suggested by the COCORP data along the Nevada-Utah border (Figure $7 \mathrm{~b}$ ).

[56] More conservatively, we could assume that a decadelong period of observation is not sufficient to reveal the full scope of behaviors, just as in the case of seismicity. Assuming all extensional strain expressed by the geodetic velocity field were relayed onto the megadetachment, we obtain an upper bound on its average slip rate of $5 \mathrm{~mm} \mathrm{a}^{-1}$. Over geologic timescales, province-wide normal faulting in the northern Great Basin has accommodated about $150 \mathrm{~km}$ of extension over the last $15 \mathrm{Ma}$ [McQuarrie and Wernicke, 2005], which under the same assumptions yields a longterm upper bound of $10 \mathrm{~mm} \mathrm{a}^{-1}$.

\subsection{Anomalous Motion of Site LEWI}

[57] The persistently low average velocity of site LEWI appears to be a case in point that, for at least one site, the last decade has not been typical of the long-term behavior. As noted in section 2.3.2, its slow average velocity was

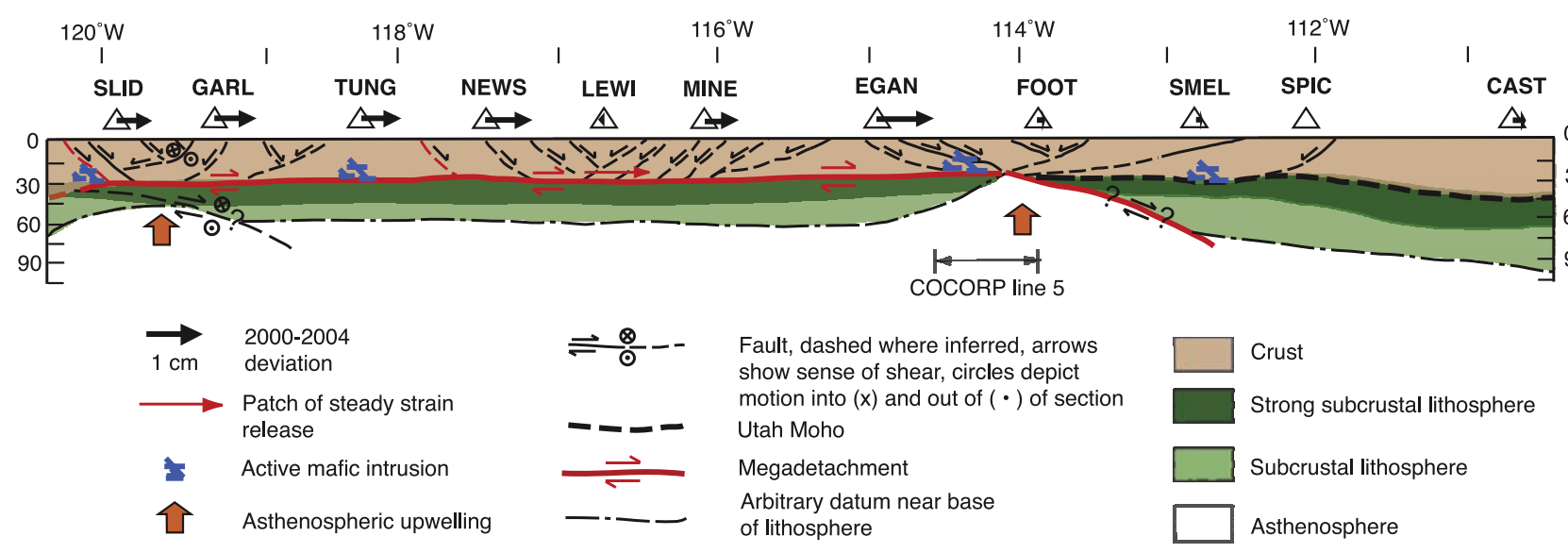

Figure 15. Cross-sectional tectonic model summarizing the primary function of the megadetachment and its relationship to active structures in the upper crust and inferred structures in the upper mantle. Section is constructed using interpretations along the COCORP $40^{\circ} \mathrm{N}$ profile (Figure 1) and data discussed in text. 
previously interpreted as either residual motion due to stress diffusion after the 1915 Pleasant Valley earthquake, or as an effect of mining-induced subsidence due to groundwater withdrawal. Problematically, if either of these processes is modeled out of LEWI's east time series, it remains linear, in contrast to the markedly nonlinear time series observed in surrounding western domain sites (Figure 5). For any stress diffusion model related to the 1915 earthquake, the temporal variation in velocity 80 to 90 years after the earthquake is at most an order of magnitude lower $\left(<0.06 \mathrm{~mm} \mathrm{a}^{-2}\right.$ [see Wernicke et al., 2000, Figure 5b]) than the rapid changes apparent in the time series of other eastern Nevada sites (of order $1 \mathrm{~mm} \mathrm{a}^{2}$ ). In addition, the difference in LEWI's average velocity in comparison with surrounding sites (1 to $2 \mathrm{~mm} \mathrm{a}^{-1} \mathrm{SE}$ ) requires spatial gradients in velocity that are too large to be explained by stress diffusion [Hammond and Thatcher, 2007].

[58] A groundwater withdrawal signal is potentially both large enough and variable enough to have a major affect on LEWI's velocity. LEWI's velocity relative to average velocities of surrounding sites is consistent in both azimuth and magnitude with that expected from subsidence associated with groundwater withdrawal in an open pit gold mining operation $20 \mathrm{~km}$ to the southeast of the site (Figure 2a) [Gourmelen et al., 2007]. However, the large subsidence signal imaged using InSAR data near the center of the mine is essentially linear from 1996.5 to 2001.5 [Gourmelen et al., 2007, Figure 1c], and hence after removing any model of its effects, as for the stress diffusion hypothesis, LEWI's time series would also remain linear, and therefore remain anomalous. Thus although both the stress diffusion and subsidence hypotheses may contribute to explaining LEWI's anomalous average velocity, neither explains why its variation in velocity contrasts with surrounding western domain sites.

[59] We therefore doubt that either of these secondary effects have somehow both slowed and linearized LEWI's motion, which instead more likely reflects a fundamental tectonic process. In the context of an extensional megadetachment, the simplest explanation of LEWI's motion is that it lies above a patch $<100 \mathrm{~km}$ wide on the detachment where yielding occurs independently of the surrounding region, in much the same manner suggested for the relatively brief anomalies at sites SLID and RUBY. In this interpretation, LEWI's observed motion is part of a longterm period of steady strain release on the megadetachment (Figure 15), with net displacement $>2.5 \mathrm{~mm} \mathrm{a}^{-1}$ if we account for upward damping of at least $20 \%$. If the patch were small, the upward damping would be considerably larger. At $60 \%$ damping, the velocity is $5 \mathrm{~mm} \mathrm{a}^{-1}$, implying that the crust immediately above the megadetachment would be moving toward North America at about $2 \mathrm{~mm} \mathrm{a}^{-1}$ during a protracted strain release event.

\section{Implications for Continental Dynamics 4.1. Constitutive Properties of the Deep Crust From Exposed Analogs}

[60] The rheological implications of some mode of crystal-plastic, stick-slip yielding near Moho depth in the Basin and Range are significant. In the subduction environment, slow earthquakes occur at temperatures of $350^{\circ} \mathrm{C}$ to $550^{\circ} \mathrm{C}$ [e.g., Dragert et al., 2004] and hence likely occur at least partly in the crystal-plastic deformation regime, assuming quartz-rich rock types are involved. Slow earthquakes have also been predicted by physical models in which frictional constitutive behavior is assumed [e.g., Liu and Rice, 2005]. Given Moho temperatures of at least $800^{\circ} \mathrm{C}$, the Great Basin megadetachment and the part of the subduction interface that generates SSEs may be rheologically analogous, with slip occurring at temperatures just above the transition from frictional to crystal plastic yielding in olivine and quartz, respectively. We grant that embrittlement via the rapid process of seismogenic, mode I crack failure occurred near the base of the crust during the Tahoe magma injection event, but in general these temperatures are likely too high for frictional sliding to predominate over dislocation and diffusion creep processes, consistent with deformation textures observed in the Lunar Craters and other xenolith suites. As elaborated further in section 4.2, our results support the hypothesis that some form of slip-weakening localization behavior, such as thermoviscous weakening, is an important process in parts of the lithosphere generally thought to deform via nonbrittle processes [Hobbs et al., 1986, 2002; Kelemen and Hirth, 2007].

\subsubsection{Ivrea-Verbano Zone}

[61] A frequently cited analog for the Basin and Range deep crust is the Ivrea-Verbano zone of northern Italy, generally regarded as the best exposure of the base of the continental crust in the world [Fountain, 1976; Snoke et al., 1999; Rutter et al., 2007]. It is an exposed cross section through a Permian rift complex about $20 \mathrm{~km}$ thick, upended during the Alpine orogeny [Rutter et al., 2007]. The deepest portion of the section contains abundant examples of hightemperature subhorizontal shear zones in silicic, mafic and ultramafic rocks [Brodie and Rutter, 1987; Rutter et al., 2007]. Exposures of the lower crust include a large mafic intrusive complex emplaced along the Moho (Mafic Formation) up to $10 \mathrm{~km}$ thick that intrudes upper amphibolite and granulite facies wall rocks (Kinzigite Formation).

[62] A key characteristic of the system is the localization of a subhorizontal shear zone along the top of the Mafic Formation that developed during its emplacement [Snoke et al., 1999], followed by postplutonic subhorizontal shearing and deformation. A duality in Permian deformational style is observed. Partial melting and granoblastic deformation textures are associated with synmagmatic deformation of wall rock granulites. Subsequently, both the Mafic and Kinzigite formations were subjected to subsolidus mylonitization on low-angle extensional shear zones developed entirely in the granulite facies, during nearly isothermal decompression of $300 \mathrm{MPa}$ during rifting [Brodie, 1995]. Within these mylonites, dynamic recrystallization of plagioclase in mafic rocks and olivine in ultramafic rocks resulted in reduction of grain size down to a few microns [Brodie, 1998].

[63] Analogy of the Ivrea-Verbano zone with the Great Basin megadetachment is imperfect, in that the Ivrea myonites are only exposed over a length scale of a few tens of kilometers, the depths of mylonitization are shallower than Basin and Range Moho depths, and the Permian magmatic flux may have been somewhat greater than the late Tertiary flux in the northern Great Basin. Nonetheless, deformation in the highest grade parts of the system near the Moho is 
characterized by strain localization in dry, isochemical shear zones, not distributed deformation with exclusively granoblastic textures. The former are far more likely to yield the strong seismic reflections observed in the deep crust in the Basin and Range [Fountain et al., 1984; Snoke et al., 1999], and demonstrate that a large magmatic flux does not inhibit strain localization and the ultimate development of mylonite.

\subsubsection{Snowbird Tectonic Zone}

[64] A second candidate for an exposed analog to a Great Basin megadetachemnt has recently been identified within the central portion of the Precambrian Snowbird tectonic zone in northern Saskatchewan, in one of the largest exposures of lower continental crust in the world [Dumond et al., 2005]. A subhorizontal shear fabric with a uniform sense of shear is developed in silicic granulites, and is exposed over an area of about $100 \mathrm{~km}^{2}$ (G. Dumond and M. L. Williams, written communication, 2007). The shear zone is at least several hundred meters thick, expressed primarily as an LS tectonite with lineation defined by ribbons of recrystallized quartz, feldspar, amphibole and pyroxene, and by aggregates of garnet. Flow is interpreted to have occurred at $700-800^{\circ} \mathrm{C}$ at paleodepths of $30-40 \mathrm{~km}$ in latest Archaean time. Relatively anhydrous conditions are indicated by the preservation of fine-grained, high-strain microstructures and a general lack of annealing or recrystallization during and after shear.

[65] The Snowbird example may not be a precise analogy to the Basin and Range in that at currently exposed levels it does not involve the upper mantle, and may have occurred in an accretionary rather than extensional setting [Dumond et al., 2005]. However, it does illustrate that large-scale subhorizontal shear zones may develop under temperature, pressure and pore fluid conditions similar to the lowermost crust of the Basin and Range, and that such zones may develop strongly foliated rocks whose deformational style includes crystal plasticity in the glide regime.

\subsubsection{Origin of LS Tectonite}

[66] If these inferences regarding the physical conditions along the megadetachment are correct, they imply that hightemperature ductile shear zones do not necessarily develop by steady state creep. LS metamorphic tectonites associated with high-temperature localization of shear commonly exhibit a distributed planar fabric ("S" surfaces of Berthe et al. [1979]) that develops coevally with localized shear planes ("C" surfaces). In light of our geodetic data, we speculate that these tectonites form primarily as a result of cycling between high and low strain rate, with $\mathrm{S}$ surfaces developing during relatively slow creep and $\mathrm{C}$ surfaces during more rapid strain release events.

[67] In the case of a Great Basin megadetachment, if steady state creep of $5 \mathrm{~mm} \mathrm{a}^{-1}$ is distributed across a zone of order $1 \mathrm{~km}$ thick, punctuated with discrete slip events at about the same rate on a highly localized zone of order $10 \mathrm{~cm}$ thick, then the (engineering) shear strain rate would alternate between $10^{-13}$ and $10^{-8} \mathrm{~s}^{-1}$. If this is the primary origin of S-C texture, then given its ubiquity in exposures of middle and lower crust, strongly variable strain rates, as opposed to steady state creep, may be the norm below the seismogenic crust. This in turn raises the possibility that the behavior of actively deforming deep crustal rocks may generally be interrogated using decadal-scale continuous GPS measurements.

\subsection{Physical Mechanism for the Formation of a Megadetachment}

[68] Given temperatures over $800^{\circ} \mathrm{C}$ near the Moho, is it plausible for the megadetachment to support greater stresses than the seismogenic crust, and for the upper mantle to be strong enough to transmit plate boundary stresses hundreds of kilometers into the plate interior? For a typical Basin and Range earthquake nucleating at $12 \mathrm{~km}$ depth, the Byerlee failure criterion assuming extending crust under hydrostatic pore fluid conditions is about $150 \mathrm{MPa}$ [e.g., Brace and Kohlstedt, 1980]. Therefore, if the region near the Moho is indeed the strongest part of the Basin and Range lithosphere, then hot, dry mafic granulite and peridotite would have to support stresses of hundreds megapascals in order to be the primary load-bearing stratum. If we interpret the deformation textures from the Lunar Craters xenoliths described earlier as evidence of low-temperature (glide only) plasticity in olivine, then deformation maps of $\sim 100 \mu \mathrm{m}$ dry olivine imply minimum stresses of hundreds of megapascals across a broad range of temperature and strain rate [e.g., Goetze, 1978]. Numerical modeling of an episodic creep mechanism in dry olivine using a variety of flow laws also suggest that the upper mantle may support yield stresses of many hundreds of megapascals under granulite facies conditions [Kelemen and Hirth, 2007]. A granulite facies lower crust or upper mantle is therefore plausibly the strongest part of the lithosphere, so long as it is dry [e.g., Maggi et al., 2000]. The dry late rift character of the lower crust in the Ivrea zone, and our data on the deformation textures and water content of olivine from the Lunar Craters xenoliths both support this hypothesis.

[69] A new, computationally intensive modeling effort has recently been developed that may explain why decoupling would localize in strong material near the Moho. This approach numerically solves the coupled energy, momentum and continuum equations for various model lithospheres, challenging traditional methods on the basis that they do not fully consider dynamic interactions that occur between brittle and ductile materials deforming within the same system [Regenauer-Lieb et al., 2006; Weinberg et al., 2007]. In these models, the competition between the storage of elastic energy and thermal dissipation in the strongest parts of the lithosphere produces unexpected feedbacks that localize strain there. Thus without any preexisting anisotropy (except that due to changing temperature and pressure), the models suggest that lithospheric deformation is controlled by horizontal decoupling horizons that develop within the strongest parts of the lithosphere, such as the middle crust and uppermost mantle. A key feature of the models is that decoupling in olivine occurs in the lowtemperature plasticity regime at granulite facies temperatures $\left(600-900^{\circ} \mathrm{C}\right)$, and is characterized by slip-weakening instabilities, not steady state flow [e.g., Regenauer-Lieb et al., 2004].

\subsection{Relationship of the Megadetachment to Sublithospheric Flow}

[70] Many workers regard it as highly unlikely that the asthenosphere is strong enough to exert significant shear 
tractions along the bases of plates [e.g., Sonder and Jones, 1999; Silver and Holt, 2002, and references therein]. If it is strong enough, an alternative hypothesis for the origin of the geodetic motions to yielding near a Moho that lies above a thin, strong subcrustal lithosphere might be yielding along or below the base of the lithosphere, perhaps including the interesting case where the base of the lithosphere lies at or above the Moho. Of the two general possibilities for mantle flow, where tractions on the base of plates either resist ("trail") or assist ("lead") plate motion, the state of stress along the Moho suggested in this study unambiguously favors mantle flow assisting westward motion of the North American plate, especially if the Moho itself is the boundary between lithosphere and an assisting asthenosphere. This is consistent with the hypothesis of westward (relative to the North American plate) return flow of asthenosphere around the foundering southern edge of the Gorda-Juan de Fuca slab as an explanation of seismic anisotropy patterns [Zandt and Humphreys, 2008].

[71] If the North American plate is resisting asthenospheric flow [e.g., Silver and Holt, 2002], then the stresses driving the megadetachment would necessarily be independent of subjacent mantle flow, and therefore must result entirely from the combined effect of tractions exerted on the plate boundary and internal body forces [e.g., Flesch et al., 2000]. It is not clear at present which of these alternatives is correct, but the greatly improved image of both upper mantle structure and geodetic velocity variations that will result from the EarthScope program may shed important new light on this question.

\subsection{Large-Scale Structure and Kinematics of Active Cordilleran Extension}

[72] Given the evidence for decoupling between crust and upper mantle discussed above, it is perhaps not surprising that the pattern of active crustal extension bears little or no relationship to the first-order structural and magmatic signals coming out of the mantle (Figure $8 b$ ). For example, the Jemez trend runs from the southern Arizona Basin and Range to the high plains of New Mexico and southern Colorado, cutting obliquely across the Rio Grande rift [Christiansen and Yeats, 1992; Roy et al., 2005]. Although much of the structure of the upper mantle may be inherited from the Proterozoic assembly of the lithosphere [Dueker et al., 2001], one possibility for the origin of the late Cenozoic magmatic trends is the development of small-scale convection, perhaps associated with one or more mantle plumes [Suppe et al., 1975; Humphreys and Dueker, 1994b; Parsons et al., 1994; Walker et al., 2004]. If this is the case, the firstorder structural pattern would be some combination of inherited Precambrian structure and negative buoyancy of the subcrustal lithosphere, influenced by plume heating or other patterns of sublithospheric flow.

[73] An alternative view would be to assume that the structural pattern in the subcrustal lithosphere, as for the crust, is primarily the result of extensional and transform tectonism within the upper mantle [e.g., Christiansen et al., 2002]. In the particular view advocated here, the production of basalt and slow $\mathrm{P}$ velocity, by analogy with mid-ocean ridges, maps out loci of localized divergence and associated upwelling within the subcrustal lithosphere. Upper mantle extension in this case reflects strain in response to both plate boundary and body forces, perhaps influenced by the northeast trending anisotropy inherited from the Proterozoic. On the basis of this assumption, the response of the intraplate lithospheric mantle to Pacific-North America transform motion is the fragmentation of the subcrustal lithosphere into a system of quasi-polygonal blocks separated by localized zones of upwelling and mechanical thinning (Figure 8b). The gradual expansion and encroachment of these zones into the North American plate, especially indicated by widespread intraplate mafic magmatism since $5 \mathrm{Ma}$ (Figure 8a), may reflect the widening influence of transform coupling between the Pacific and North American plates.

[74] The primary virtue of this model as regards megadetachments is that the discordance between crustal and mantle strain requires them (Figure 14). In the specific case of a Great Basin megadetachment, we speculate that it links localized thinning of the mantle lithosphere along the St. George/Utah trend (including western Utah) with active extension in northwestern Nevada (Figures $8 b$ and 15). The map in Figure $8 \mathrm{~b}$ suggests that even parts of the Great Plains and Colorado Plateau would be subject to detachment given the discordance of the Jemez trend and the Rio Grande Rift, although the strain rates in this region are quite low.

[75] The localized pattern of upper mantle extensional strain inferred from low $\mathrm{P}$ wave velocity and magmatism in the western United States is consistent with interpretations of reflection profiles from the Mesozoic extensional province around the British Isles, mainly acquired in the marine environment. These profiles imaged numerous strong, discrete dipping reflections in the subcrustal lithosphere, which is otherwise unreflective [McGeary and Warner, 1985]. Although interpretations are nonunique and often differ in detail, the general pattern has been interpreted as evidence for localized strain in the upper mantle, at least some of which occurred during the rifting episode [e.g., Wernicke, 1985; Klemperer, 1988; Reston, 1990; Flack et al., 1990]. Although similar reflections have not been observed in the upper mantle in the Basin and Range, it is possible if not probable that noise levels in the Basin and Range COCORP data at these depths were too high to produce clear images of continuous upper mantle reflections [Klemperer et al., 1986].

[76] In support of this "plate tectonic" origin for upper mantle structure, as opposed to the influence of plumes, we note that one of the strongest arguments for the presence of a plume focused on Yellowstone is the hot spot track defined by the northeastward propagation of silicic volcanic centers along the Snake River Plain [e.g., Suppe et al., 1975; Parsons et al., 1994; Anders, 1994]. However, propagation is also characteristic of mechanical extension in both the oceanic and continental lithosphere [e.g., Hey, 1977; Hey et al., 1992; Glazner and Bartley, 1984; Wernicke, 1992]. The Yellowstone hot spot track is mirrored by northwestward propagation of rhyolitic magmatism across eastern Oregon [Christiansen et al., 2002; Jordan et al., 2004], which is not easily reconciled with a simple plume track. Seismic images of the upper mantle in the Snake River Plain/Yellowstone region show an elongate, narrow zone of low velocities surrounded by relatively fast mantle on either side, rather than a broad dome of low velocity 
[Saltzer and Humphreys, 1997; Christiansen et al., 2002], and there is little disruption of the regional northeast trend in shear wave splitting around the active Yellowstone magmatic center, as might be expected from strong upwelling from deep in the mantle [Waite et al., 2005]. Further, basaltic lavas younger than $5 \mathrm{Ma}$ in the Yellowstone, St. George and Jemez trends show no clear pattern of temporal migration [Christiansen et al., 2002].

[77] Given these difficulties for a plume origin for upper mantle structure, plate-driven mechanical extension as the origin of melting and thinning of the lithosphere merits serious consideration. Small-scale convection is clearly an important element to both the structural and magmatic evolution, but the best documented examples, such as the southern Sierra Nevada region [Zandt et al., 2004] and eastern Oregon [Hales et al., 2005] occur following the onset of profound mechanical extension of the upper crust in adjacent areas of the Basin and Range province, suggesting that extension is an important stimulus [Buck, 1986], for example as in thermomechanical models of the removal of the dense, eclogitic root of the Sierran batholith [Le Pourhiet et al., 2006]. Hence we favor disharmonic extension, modified by buoyancy-driven removal [Wernicke, 1990, 1992] as the primary control on the late Cenozoic structure of the subcrustal lithosphere.

\subsection{Fluid Crustal Layer}

[78] It is generally accepted that from Eocene to late Miocene time in the Basin and Range province, large lateral gradients in upper crustal thinning developed without the extreme changes in crustal thickness and topography predicted by the uniform crustal stretching model of McKenzie [1978] and its variants. The dramatic failure of the uniform stretching model in the Basin and Range [Wernicke, 1985] ultimately led to a consensus that a complementary vertical strain field developed in the deep crust, whose flow was governed by the flotation of upper crustal blocks within it (see historical overview by Wernicke [1992, pp. 567-572]). This raises the issue of whether such flow is still occurring within the Basin and Range crust, and if so how it bears on the megadetachment hypothesis. The viscosity models based on the isostatic rebound of Pleistocene lakes Lahontan and Bonneville described in section 2.6.2 all suggest monotonically decreasing viscosity in the upper $100 \mathrm{~km}$ [Bills et al., 2007]. The sensitivity of these models to a 10to $20-\mathrm{km}$-thick layer of very weak deep crust has not been explored, but there are several other lines of evidence that bear strongly on this question.

[79] A fluid crustal layer is most likely to develop in areas where the crust is both thick and hot [Block and Royden, 1990; Wernicke, 1990; Kruse et al., 1991; Buck, 1991]. The progressive cooling and strengthening of the crust during extension [Sonder and England, 1989] limits its ability to flow in response to pressure gradients, and therefore large upper crustal blocks between extensional domains that had previously been afloat in weak, quartzose, crustal asthenosphere eventually become stranded atop a much stronger mafic and ultramafic substrate, as a result of both hydraulic evacuation from beneath the blocks and overall cooling due to upward advection (see Wernicke [1990, Figure 12] or Wernicke [1992, Figure 8] for kinematic examples). According to the calculations of Kruse et al. [1991], temperatures of at least $700^{\circ} \mathrm{C}$ are required for channel flows to be significant in quartz-rich rocks, and of course, much higher temperatures are required for mafic and ultramafic rocks. The Basin and Range geotherm of Lachenbruch and Sass [1978] places the $700^{\circ} \mathrm{C}$ isotherm at about $25 \mathrm{~km}$ depth, which is about the same as the maximum depth of crust that is potentially quartzofeldspathic ( $\mathrm{P}$ wave velocities of 6.0 to $6.6 \mathrm{~km} \mathrm{~s}^{-1}$ ) [Catchings and Mooney, 1991; Holbrook et al., 1991], and so any modern channel would be at most only a few kilometers thick. The viscosity required for effective channel flow scales with the cube of channel thickness [Kruse et al., 1991, equation (5)], and as such even if flow is still taking place, it is unlikely to be significant in a channel thinner than $10 \mathrm{~km}$ [Kruse et al., 1991]. The ability of such a channel to redistribute mass would be quite limited, even if flow were somehow rapid.

[80] The tectonic and magmatic setting of the present-day Basin and Range also militates against the existence of thick channel flows. In contrast to the mid-Tertiary phase of extension, which was strongly heterogeneous and accompanied by voluminous regional magmatism, Pliocene and Quaternary extension has been more evenly distributed and accompanied by a lower magmatic flux, especially as regards silicic magmas. Because both the driving forces for significant channel flow and the heat necessary to weaken a large volume of crust are absent, compensating flow in the present-day northern Great Basin is probably restricted to the asthenospheric mantle [e.g., Wernicke, 1990; Buck, 1991]. On the basis of this reasoning, our model for active deformation (Figure 15), following Wernicke [1990], interprets the modern range-bounding faults as hanging wall splays to a megadetachment, rather than bottoming out into a thick layer of weak, diffusely stretching crust from 15 to $30 \mathrm{~km}$ depth.

[81] The seismic reflection data in the Basin and Range do not support a direct connection between upper crustal faults and the Moho along the transect, except for the Schell Creek and Egan Range faults, which appear to affect the entire crust (Figure 7) [Hauser et al., 1987]. Further, the ubiquitous subhorizontal fabric beneath much of Nevada below $15 \mathrm{~km}$ depth clearly supports diffuse stretching or channel flow. We suggest that much of this fabric in the reflection data is either due to magmatic injection, or to strong province-wide channel flows that developed in midTertiary time but which are now inactive. We follow Hauser et al. [1987] in interpreting the west tilted "G reflections" in Figure 7 as indicative of block faulting of the entire crust, prior to injection of subhorizontal sills in the same area.

\subsection{Microplates or a Continuum?}

[82] The breakdown of plate tectonics in describing diffuse continental deformation poses the question of whether the active tectonics of these regions are best described as a continuum, or as a system of "microplates" whose motions may be quantified and integrated into the global plate circuit [McKenzie, 1972; Molnar and Tapponnier, 1975; Smith, 1978; England and McKenzie, 1982; Thatcher, 1995; Tapponnier et al., 2001]. Certain large, subcontinental blocks within wide orogens appear to behave as microplates in terms of their surface deformation and seismicity, such as the Apulian, Tarim, Sierra Nevada-Great Valley, or Colorado Plateau "lithospheric blocks." 
[83] Primarily on the basis of the distribution of earthquakes, Smith [1978] proposed a subdivision of western North American lithosphere into four subplates including the Sierra Nevada, Great Basin-High Lava Plains, Colorado Plateau, and Northern Rocky Mountain-Columbia Plateau subplates. Although differing in detail, Smith's [1978] subdivision is similar to the pattern of heterogeneous upper mantle deformation suggested in Figure 8b. The differences arise from the fact that regions of low $\mathrm{P}$ velocity and young magmatism are not entirely coincident with the localized pattern of recorded seismic strain release. For example, northeastern Oregon and east central Arizona have very low seismicity, but are magmatically active and overlie low $\mathrm{P}$ wave anomalies. Strain release at the million-year timescale is far more diffuse than the modern belt-like pattern of numerous small $(\mathrm{M}<5)$ earthquakes. Therefore the modern earthquake belts (e.g., the Intermountain Seismic Belt in central Utah) may reflect a continuous chatter of low moment release rate that is in some way driven by upper mantle structure [e.g., Lowry and Smith, 1995] but is not representative of the long-term $(100,000$ years and greater) pattern of upper crustal strain release.

[84] The pattern suggested by Figures $8 \mathrm{~b}$ and 15 gives pause as to whether not only large blocks such as the Colorado Plateau, but especially features such as the central Great Basin (eastern Nevada), should be regarded as stable lithospheric blocks. By the criteria (1) average geodetic velocity, and (2) seismicity, the eastern Nevada lithosphere may be defined as a "block." But if one considers the additional criteria (3) total Quaternary strain and (4) active decoupling, it is anything but a simple block In this case, the lithosphere is being sheared in half by a structure that is not detectable through the first two criteria. Overall, the deforming western U.S. lithosphere is poorly described as either a sheet-like viscous continuum or a system of blocks.

\section{Conclusions}

[85] The primary result of this synthesis is the proposal of a top-to-the-east, subhorizontal detachment that coherently releases elastic strain energy in the lithosphere across a 500-km width of a diffuse plate boundary deformation zone. This dimension is much larger than the aperture of deformation and strain associated with intraplate earthquakes. A key test of the hypothesis will be the next decade of continuous GPS measurements from the Plate Boundary Observatory component of EarthScope. If as we suspect slip events are detectable over most of Nevada and eastern California, they will be the areally largest tectonic strain release events ever observed. The kinematic function of the megadetachment over such a broad area suggests that it lies within the loadbearing part of the system and controls energy transfer, and therefore the time and location of intraplate earthquakes on the hundred or so individual fault segments it underlies. Given the function of the structure as a large-scale, uniform sense shear zone, its broadest implication is that deformation of the lithosphere is controlled by crystal-plastic rheologies below the seismogenic layer, and is disharmonic between crust and mantle (Figures 8b, 11, 14, and 15).

[86] The apparent directivity of slip, initiating and ending near the center of the intraplate deformation zone near site RUBY, and climaxing along the western margin of the
Basin and Range nearer to the plate boundary, hints at a net transfer of energy from the center of the orogen toward the plate boundary. If plate boundary tractions were the only important influence on deformation one might expect propagation inward rather that outward. However, estimates of the other available source of energy, gravitiational potential, is quite high in the proposed source region near site RUBY. There, the lithospheric gravitational potential is estimated to be $>2 \times 10^{12} \mathrm{~N} \mathrm{~m}^{-1}$, whereas at site SLID it is only $1 \times$ $10^{12} \mathrm{~N} \mathrm{~m}^{-1}$, and even lower as the plate boundary itself is approached [Jones et al., 1996; see Sonder and Jones, 1999, Figure 4]. In general, some of the highest values of lithospheric potential energy in the western U.S. occur in eastern Nevada, generally declining from east to west toward the plate boundary in California.

[87] An interesting implication of our data derives from considering its energy release in comparison to the energy release from late Quaternary faulting in the upper crust. The decadal energy release along the detachment is of the same order of magnitude as an upper crustal earthquake, which occurs on average every 100 years at a given latitude in the Basin and Range. If the decadal energy release on the detachment occurs over a latitudinal range of $500 \mathrm{~km}$, then the energy release rate per century for the detachment is the same order of magnitude as the energy release rate for ten $50-\mathrm{km}$-long fault segments (between $10^{27}$ and $10^{28} \mathrm{dyn} \mathrm{cm}$ ).

[88] However, as mentioned in section 3.3, our estimate of the displacement rate due to yielding (i.e., westward slowing) over the last decade of $1 \mathrm{~mm} \mathrm{a}^{-1}$ is only $20 \%$ of the total difference in west velocities across Nevada over the same time interval. This difference, though large, is still within the uncertainties of our order-of-magnitude estimates of energy release. If the $1 \mathrm{~mm} \mathrm{a}^{-1}$ rate is much slower than average, then geodetically speaking the structure is something of a "sleeping giant" capable of much larger regional strain events, perhaps of order $10 \mathrm{~mm} \mathrm{a}^{-1}$ for 5 years, especially during periods of rapid strain release in the upper crust. During the 39-year period from 1915 to 1954, when most of the major ruptures of the central Nevada seismic belt occurred, the system certainly displayed large coseismic and postseismic strain transients in the vicinity of the earthquakes. Given the remarkably large spatial scale of coherent slowing associated with the Tahoe magmatic injection event in 2003 [Davis et al., 2006], we suspect that much larger regional transients may have occurred along the megadetachment over those four decades. The "sleeping giant" hypothesis for the megadetachment predicts that sustained, rapid slowing of the entire region occurs periodically, with behavior akin to the local behavior of individual sites LEWI (sustained slowing of $5 \mathrm{~mm} \mathrm{a}^{-1}$, accounting for upward damping) and SLID (slowing at the rapid rate of $20 \mathrm{~mm} \mathrm{a}^{-1}$ for 0.5 year).

[89] The broadest methodological implication of our results is the potential of continuous GPS to interrogate active tectonic processes well below seismogenic depths. Other broad regions of continental deformation probably deform in a similar mode, opening up an exciting new frontier for probing the inner workings of the ductile regime and better understanding the relationship between the seismogenic lithosphere and its substrate. Variations in both horizontal and vertical surface velocities, once periodic meteorological and hydrological signals can be recognized 
and modeled out, are primarily sensitive to large-scale motions within the subseismogenic lithosphere. Constraining these motions, which now appear as mere assumptions in physical models of the seismic cycle, is prerequisite to a rigorous mechanics.

[90] High-accuracy continuous GPS data with BARGENtype network geometry and signal processing methods are crucial, but also quite limited in the absence of a spectrum of other geometric and kinematic data. The most informative images of the active tectonics of deep continental structure will likely result from comparing regional velocity changes with (1) the characteristics of swarms of small crustal earthquakes, (2) the late Quaternary/historic energy release pattern in the upper crust, (3) both active and passive seismic images of potential structures, and (4) chemical imaging of Earth structure using mafic magmas and xenoliths. In the present study, each of these elements was essential in locating the source of the geodetic anomalies and in interpreting its function.

[91] Acknowledgments. This research was supported by National Science Foundation grant EAR-04-53975, DOE cooperative agreement DE-FC28-03RW12232 (Task 3), and the Caltech Tectonics Observatory. Geodetic sites were constructed with technical assistance from the University NAVSTAR Consortium (UNAVCO) facility. The time series for site KTBW were obtained from the PANGA Data Analysis Facility Web site (http://www.panga.cwu.edu/). The time series for site ACAP were obtained from K. Larson. We are grateful to S. Klemperer for prepublication copies of seismic imaging studies in the northern Great Basin and G. Dumond and M. Williams for permission to discuss unpublished data from the Snowbird tectonic zone. We thank Associate Editor W. Schellart and formal reviewers W. Hammomd, P. England, and S. Wesnousky for comments that substantially improved the presentation. We also thank S. Kidder and D. Anderson for comments on an early draft of the manuscript and M. Simons, M. Gurnis, J. Saleeby, and D. Helmberger for useful discussions.

\section{References}

Allmendinger, R. W., T. A. Hauge, E. C. Hauser, C. J. Potter, S. L. Klemperer, K. D. Nelson, P. Knuepfer, and J. Oliver (1987), Overview of the COCORP $40^{\circ} \mathrm{N}$ Transect, western United States: The fabric of an orogenic belt, Geol. Soc. Am. Bull., 98, 308-319, doi:10.1130/00167606(1987) $98<308$ :OOTCNT $>2.0 . C O ; 2$.

Anders, M. H. (1994), Constraints on North American plate velocity from the Yellowstone hotspot deformation field, Nature, 369, 53-55, doi: $10.1038 / 369053 \mathrm{a} 0$.

Axen, G. J., J. Selverstone, T. Byrne, and J. Fletcher (1998), If the strong crust leads, will the weak crust follow?, GSA Today, 8, 1-8.

Beaumont, C., R. A. Jamieson, M. H. Nguyen1, and B. Lee (2001), Himalayan tectonics explained by extrusion of a low-viscosity crustal channel coupled to focused surface denudation, Nature, 414, 738-742, doi:10.1038/414738a.

Beghoul, N., M. Barazangi, and B. L. Isacks (1993), Lithospheric structure of Tibet and western North America: Mechanisms of uplift and a comparative study, J. Geophys. Res., 98, 1997-2016, doi:10.1029/ 92JB02274

Bell, D. R., and G. R. Rossman (1992), Water in Earth's mantle: The role of nominally anhydrous minerals, Science, 255, 1391-1397, doi:10.1126/ science.255.5050.1391.

Bell, J. W., S. J. Caskey, A. R. Ramelli, and L. Guerrieri (2004), Pattern and rates of faulting in the central Nevada seismic belt, and paleoseismic evidence for prior beltlike behavior, Bull. Seismol. Soc. Am., 94, 1229-1254, doi:10.1785/012003226.

Bennett, R. A., B. P. Wernicke, and J. L. Davis (1998), Continuous GPS measurements of contemporary deformation across the northern Basin and Range province, Geophys. Res. Lett., 25(4), 563-566, doi:10.1029/98GL00128.

Bennett, R. A., J. L. Davis, and B. P. Wernicke (1999), Present-day pattern of Cordilleran deformation in the western United States, Geology, 27, 371-374, doi:10.1130/0091-7613(1999)027<0371:PDPOCD>2.3.CO;2.

Bennett, R. A., B. P. Wernicke, N. A. Niemi, A. M. Friedrich, and J. L. Davis (2003), Contemporary strain rates in the northern Basin and Range province from GPS data, Tectonics, 22(2), 1008, doi:10.1029/ $2001 \mathrm{TC} 001355$
Bergman, S. C. (1982), Petrogenetic aspects of the alkali basaltic lavas and included megacrysts and nodules from the Lunar Crater volcanic field, Nevada, U. S. A., Ph.D. thesis, 432 pp., Princeton Univ., Princeton, N. J.

Bergman, S. C., K. A. Foland, and F. J. Spera (1981), On the origin of an amphibole-rich vein in a peridotite inclusion from the Lunar Crater volcanic field, Nevada, USA, Earth Planet. Sci. Lett., 56, 343-361, doi:10.1016/0012-821X(81)90139-4.

Berthe, D., P. Choukroune, and P. Jegouzo (1979), Orthogneiss, mylonite and non coaxial deformation of granites: the example of the South Armorican Shear Zone, J. Struct. Geol., 1, 31-42, doi:10.1016/01918141(79)90019-1.

Bills, B. G., K. D. Adams, and S. G. Wesnousky (2007), Viscosity structure of the crust and upper mantle in western Nevada from isostatic rebound patterns of the late Pleistocene Lake Lahontan high shoreline, J. Geophys. Res., 112, B06405, doi:10.1029/2005JB003941.

Block, L., and L. H. Royden (1990), Core complex geometries and regional scale flow in the lower crust, Tectonics, 9, 557-567, doi:10.1029/ TC009i004p00557.

Brace, W. F., and D. L. Kohlstedt (1980), Limits on lithospheric stress imposed by laboratory experiments, J. Geophys. Res., 85, 6248-6252, doi:10.1029/JB085iB11p06248

Brodie, K. H. (1995), The development of orientated symplectites during deformation, J. Metamorph. Geol., 13, 499-508, doi:10.1111/j.15251314.1995.tb00237.x.

Brodie, K. H. (1998), High-temperature mylonites, in Fault-Related Rocks: A Photographic Atlas, edited by A. W. Snoke et al., pp. 428-441, Princeton Univ. Press, Princeton, N. J.

Brodie, K. H., and E. H. Rutter (1987), Deep crustal extensional faulting in the Ivrea Zone of northern Italy, Tectonophysics, 140, 193-212, doi:10.1016/0040-1951(87)90229-0.

Buck, W. R. (1986), Small-scale convection induced by passive rifting - the cause for uplift of rift shoulders, Earth Planet. Sci. Lett., 77, 362-372, doi:10.1016/0012-821X(86)90146-9.

Buck, W. R. (1991), Modes of continental lithospheric extension, J. Geophys. Res., 96, 20,161-20,178, doi:10.1029/91JB01485.

Burchfiel, B. C., Deng Q., P. Molnar, L. Royden, Wang Y., Zhang P., and Zhang W. (1989), Intracrustal detachment within zones of continental deformation, Geology, 17, 748-752, doi:10.1130/0091-7613(1989)017< 0448:IDWZOC $>2.3$.CO;2.

Caskey, S. J., J. W. Bell, A. R. Ramelli, and S. G. Wesnousky (2004), Historic surface faulting and paleoseismicity in the area of the 1954 Rainbow Mountain-Stillwater earthquake sequence, central Nevada, Bull. Seismol. Soc. Am., 94, 1255-1275, doi:10.1785/012003012.

Catchings, R. D., and W. D. Mooney (1991), Basin and Range crustal and upper mantle structure, northwest to central Nevada, J. Geophys. Res., 96, 6247-6267, doi:10.1029/91JB00194

Christiansen, R. L., and R. S. Yeats (1992), Post-Laramide geology of the U. S. Cordilleran region, in The Geology of North America, vol. G3, The Cordilleran Orogen: Conterminus U.S., edited by B. C. Burchfiel et al., pp. 261-406, Geol. Soc. of Am., Boulder, Colo.

Christiansen, R. L., G. R. Foulger, and J. R. Evans (2002), Upper mantle origin of the Yellowstone hotspot, Geol. Soc. Am. Bull., 114, 1245-1256, doi:10.1130/0016-7606(2002)114<1245:UMOOTY>2.0.CO;2.

Cook, F. A., D. S. Albaugh, L. D. Brown, S. Kaufman, J. E. Oliver, and R. D. Hatcher Jr. (1979), Thin-skinned tectonics in the crystalline southern Appalachians; COCORP seismic-reflection profiling of the Blue Ridge and Piedmont, Geology, 7, 563-567, doi:10.1130/00917613(1979)7<563:TTITCS $>2.0$. CO;2.

Davis, D., J. Suppe, and F. A. Dahlen (1983), Mechanics of fold-and-thrust belts and accretionary wedges, J. Geophys. Res., 88, 1153-1172, doi:10.1029/JB088iB02p01153.

Davis, J. L., R. A. Bennett, and B. P. Wernicke (2003), Assessment of GPS velocity accuracy for the Basin and Range Geodetic Network (BARGEN), Geophys. Res. Lett., 30(7), 1411, doi:10.1029/2003GL016961.

Davis, J. L., B. P. Wernicke, S. Bisnath, N. A. Niemi, and P. Elósegui (2006), Subcontinental-scale crustal velocity changes along the PacificNorth America plate boundary, Nature, 441, 1131-1134, doi:10.1038/ nature04781.

DeCelles, P. G., D. M. Robinson, J. Quade, T. P. Ojha, C. N. Garzione, P. Copeland, and B. N. Upreti (2001), Stratigraphy, structure, and tectonic evolution of the Himalayan fold-thrust belt in western Nepal, Tectonics, 20, 487-509, doi:10.1029/2000TC001226.

Demouchy, S., S. D. Jacobsen, F. Gaillard, and C. R. Stern (2006), Rapid magma ascent recorded by water diffusion profiles in mantle olivine, Geology, 34, 429-432, doi:10.1130/G22386.1.

dePolo, C. M., and J. G. Anderson (2000), Estimating the slip rates of normal faults in the Great Basin, USA, Basin Res., 12, 227-240, doi:10.1046/j.1365-2117.2000.00131.x. 
Dixon, J. E., T. H. Dixon, D. R. Belb, and R. Malservisi (2004), Lateral variation in upper mantle viscosity: Role of water, Earth Planet. Sci. Lett., 222, 451-467, doi:10.1016/j.epsl.2004.03.022.

Dokka, R. K., and C. J. Travis (1990), Role of the eastern California shear zone in accommodating Pacific-North American plate motion, Geophys. Res. Lett., 17, 1323-1326, doi:10.1029/GL017i009p01323.

Dragert, H., K. Wang, and G. Rogers (2004), Geodetic and seismic signatures of episodic tremor and slip in the northern Cascadia subduction zone, Earth Planets Space, 56, 1143-1150.

Ducea, M. N., and J. B. Saleeby (1996), Buoyancy sources for a large, unrooted mountain range, the Sierra Nevada, California: Evidence from xenolith thermobarometry, J. Geophys. Res., 101, 8229-8244, doi:10.1029/95JB03452.

Ducea, M., and J. Saleeby (1998), A case for delamination of the deep batholithic crust beneath the Sierra Nevada, California, Int. Geol. Rev. 40, 78-93.

Dueker, K., H. Yuan, and B. Zurek (2001), Thick-structured Proterozoic lithosphere of the Rocky Mountain region, GSA Today, 11, 4-9, doi:10.1130/1052-5173(2001)011<0004:TSPLOT > 2.0.CO;2.

Dumond, G., P. Gonclaves, M. L. Williams, and S. A. Bowring (2005), Field-based constraints on lower crustal flow from the world's largest exposure of lower continental crust, northern Saskatchewan, Canada, Eos Trans. $A G U, 86(52)$, Fall Meet. Suppl., Abstract V21A-0592.

Elósegui, P., J. L. Davis, J. X. Mitrovica, R. A. Bennett, and B. P. Wernicke (2003), Crustal loading near Great Salt Lake, Utah, Geophys. Res. Lett. 30(3), 1111, doi:10.1029/2002GL016579.

England, P., and D. McKenzie (1982), A thin viscous sheet model for continental deformation, Geophys. J. R. Astron. Soc., 70, 295-321, doi:10.1111/j.1365-246X.1982.tb04969.x.

England, P., G. Houseman, and L. Sonder (1985), Length scales for continental deformation in convergent, divergent, and strike-slip environments: Analytical and approximate solutions for a thin viscous sheet model, J. Geophys. Res., 90(B5), 3551-3557, doi:10.1029/ JB090iB05p03551.

Flack, C. A., S. L. Klemperer, S. E. McGeary, D. B. Snyder, and M. R. Warner (1990), Reflections from mantle fault zones around the British Isles, Geology, 18, 528-532, doi:10.1130/0091-7613(1990)018<0528: RFMFZA $>2.3 . \mathrm{CO} ; 2$.

Flesch, L. M., W. E. Holt, A. J. Haines, and B. Shen-Tu (2000), Dynamics of the Pacific-North American plate boundary in the western United States, Science, 287, 834-836, doi:10.1126/science.287.5454.834.

Flesch, L. M., W. E. Holt, A. J. Haines, L. Wen, and B. Shen-Tu (2007), The dynamics of western North America: Stress magnitudes and the relative role of gravitational potential energy, plate interaction at the boundary and basal tractions, Geophys. J. Int., 169, 866-896, doi:10.1111/j.1365-246X.2007.03274.x.

Fountain, D. M. (1976), The Ivrea-Verbano and Strona-Ceneri zones, northern Italy: A cross-section of the continental crust-New evidence from seismic velocities of rock samples, Tectonophysics, 33, 145-165, doi:10.1016/0040-1951(76)90054-8.

Fountain, D. M., C. A. Hurich, and S. B. Smithson (1984), Seismic reflectivity of mylonite zones in the crust, Geology, 12, 195-198, doi:10.1130/ 0091-7613(1984)12<195:SROMZI $>2.0 . \mathrm{CO} ; 2$

Frankel, K. L., et al. (2007), Cosmogenic ${ }^{10} \mathrm{Be}$ and ${ }^{36} \mathrm{Cl}$ geochronology of offset alluvial fans along the northern Death Valley fault zone: Implications for transient strain in the eastern California shear zone, J. Geophys. Res., 112, B06407, doi:10.1029/2006JB004350.

Freed, A. M., R. Bürgmann, and T. Herring (2007), Far-reaching transient motions after Mojave earthquakes require broad mantle flow beneath a strong crust, Geophys. Res. Lett., 34, L19302, doi:10.1029/2007GL030959.

Friedrich, A. M., B. P. Wernicke, N. A. Niemi, R. A. Bennett, and J. L. Davis (2003), Comparison of geodetic and geologic data from the Wasatch region, Utah, and implications for the spectral character of Earth deformation at periods of 10 to 10 million years, J. Geophys. Res., 108(B4), 2199, doi:10.1029/2001JB000682.

Friedrich, A. M., J. Lee, B. P. Wernicke, and K. Sieh (2004), Geologic context of geodetic data across a Basin and Range normal fault, Crescent Valley, Nevada, Tectonics, 23, TC2015, doi:10.1029/2003TC001528.

Gan, W., P. Zhang, Z.-K. Shen, Z. Niu, M. Wang, Y. Wan, D. Zhou, and J. Cheng (2007), Present-day crustal motion within the Tibetan Plateau inferred from GPS measurements, J. Geophys. Res., 112, B08416, doi:10.1029/2005JB004120.

Gashawbeza, E. M., S. L. Klemperer, C. K. Wilson, and E. L. Miller (2008), Nature of the crust beneath northwest Basin and Range province from teleseismic receiver function data, J. Geophys. Res., 113, B10308, doi:10.1029/2007JB005306

Glazner, A. F., and J. M. Bartley (1984), Timing and tectonic setting of Tertiary low-angle normal faulting and associated magmatism in the southwestern United States, Tectonics, 3, 385-396, doi:10.1029/ TC003i003p00385.
Goetze, C. (1978), Mechanisms of creep in olivine, Philos. Trans. R. Soc London, Ser. A, 288, 99-119.

Gourmelen, N., F. Amelung, F. Casu, M. Manzo, and R. Lanari (2007), Mining-related ground deformation in Crescent Valley, Nevada: Implications for sparse GPS networks, Geophys. Res. Lett., 34, L09309, doi:10.1029/2007GL029427.

Gripp, A. E., and R. G. Gordon (1990), Current plate velocities relative to the hotspots incorporating the Nuvel-1 global plate motion model, Geophys. Res. Lett., 17, 1109-1112, doi:10.1029/GL017i008p01109.

Gripp, A. E., and R. G. Gordon (2002), Young tracks of hotspots and current plate velocities, Geophys. J. Int., 150, 321-361, doi:10.1046/ j.1365-246X.2002.01627.x.

Hales, T. C., D. L. Abt, E. D. Humphreys, and J. J. Roering (2005), A lithospheric instability origin for Columbia River flood basalts and Wallowa Mountains uplift in northeast Oregon, Nature, 438, 842-845, doi:10.1038/nature04313.

Hammond, W. C., and W. Thatcher (2004), Contemporary tectonic deformation of the Basin and Range province, western United States: 10 years of observation with the Global Positioning System, J. Geophys. Res., 109, B08403, doi:10.1029/2003JB002746.

Hammond, W. C., and W. Thatcher (2007), Crustal deformation across the Sierra Nevada, northern Walker Lane, Basin and Range transition, western United States measured with GPS, 2000-2004, J. Geophys. Res., 112, B05411, doi:10.1029/2006JB004625.

Hauge, T. A., et al. (1987), Crustal structure of western Nevada from COCORP deep seismic-reflection data, Geol. Soc. Am. Bull., 98, 320329, doi:10.1130/0016-7606(1987)98<320:CSOWNF>2.0.CO;2.

Hauser, E., et al. (1987), Crustal structure of eastern Nevada from COCORP deep seismic reflection data, Geol. Soc. Am. Bull., 99, 833-844, doi:10.1130/0016-7606(1987)99<833:CSOENF>2.0.CO;2

Hetland, E. A., and B. H. Hager (2003), Postseismic relaxation across the Central Nevada Seismic Belt, J. Geophys. Res., 108(B8), 2394, doi:10.1029/2002JB002257.

Hey, R. N. (1977), Tectonic Evolution of Cocos-Nazca spreading center, Geol. Soc. Am. Bull., 88, 1404-1420, doi:10.1130/0016-7606(1977)88< 1404:TEOTCS $>2.0 . \mathrm{CO} ; 2$

Hey, R. N., et al. (1992), Alvin investigation of an active propagating rift system, Galapagos 95.5 W, Mar. Geophys. Res., 14, 207-226, doi:10.1007/BF01270630.

Hirth, G., and D. L. Kohlstedt (1996), Water in the oceanic upper mantle: Implications for rheology, melt extraction and the evolution of the lithosphere, Earth Planet. Sci. Lett., 144, 93-108, doi:10.1016/0012821X(96)00154-9.

Hobbs, B. E., A. Ord, and C. Teyssier (1986), Earthquakes in the ductile regime?, Pure Appl. Geophys., 124, 309-336, doi:10.1007/BF00875730.

Hobbs, B. E., H. Tanaka, and Y. Iio (2002), Acceleration of slip motion in deep extensions of seismogenic faults in and below the seismogenic region, Earth Planets Space, 54, 1195-1205.

Holbrook, W. S. (1990), The crustal structure of the northwestern Basin and Range province, Nevada, from wide-angle seismic data, J. Geophys. Res., 95, 21,843-21,869, doi:10.1029/JB095iB13p21843.

Holbrook, W. S., R. D. Catchings, and C. M. Jarchow (1991), Origin of deep crustal reflections - Implications of coincident seismic refraction and reflection data in Nevada, Geology, 19, 175-179, doi:10.1130/00917613(1991)019<0175:OODCRI > 2.3.CO;2.

Humphreys, E. D., and K. G. Dueker (1994a), Western United-States upper-mantle structure, J. Geophys. Res., 99, 9615-9634, doi:10.1029/ 93JB01724

Humphreys, E. D., and K. G. Dueker (1994b), Physical state of the western United-States upper-mantle, J. Geophys. Res., 99, 9635-9650, doi:10.1029/93JB02640.

Humphreys, E., E. Hessler, K. Dueker, G. L. Farmer, E. Erslev, and T. Atwater (2003), How Laramide-age hydration of North American lithosphere by the Farallon slab controlled subsequent activity in the western United States, Int. Geol. Rev., 45, 575-595, doi:10.2747/00206814.45 .7 .575

Jackson, J. (2002), Faulting, flow, and the strength of the continental lithosphere, Int. Geol. Rev., 44, 39-61, doi:10.2747/0020-6814.44.1.39.

Jarchow, C. M., G. A. Thompson, R. D. Catchings, and W. D. Mooney (1993), Seismic evidence for active magmatic underplating beneath the Basin and Range province, western United States, J. Geophys. Res., 98, 22,095-22,108, doi:10.1029/93JB02021.

Jones, C. H., J. R. Unruh, and L. J. Sonder (1996), The role of gravitational potential energy in active deformation in the southwestern United States, Nature, 381, 37-41, doi:10.1038/381037a0.

Jordan, B. T., A. L. Grunder, R. A. Duncan, and A. L. Deino (2004), Geochronology of age-progressive volcanism of the Oregon High Lava Plains: Implications for the plume interpretation of Yellowstone, J. Geophys. Res., 109, B10202, doi:10.1029/2003JB002776. 
Katayama, I., H. Jung, and S. Karato (2004), New type of olivine fabric from deformation experiments at modest water content and low stress, Geology, 32, 1045-1048, doi:10.1130/G20805.1.

Kelemen, P. B., and G. Hirth (2007), A periodic shear-heating mechanism for intermediate-depth earthquakes in the mantle, Nature, 446, 787-790, doi: 10.1038 /nature 05717

Klemperer, S. L. (1988), Crustal thinning and nature of extension in the northern North Sea from deep seismic-reflection profiling, Tectonics, 7 , 803-821, doi:10.1029/TC007i004p00803.

Klemperer, S. L., T. A. Hauge, E. C. Hauser, J. E. Oliver, and C. J. Potter (1986), The Moho in the northern Basin and Range province, Nevada, along the COCORP $40^{\circ} \mathrm{N}$ seismic-reflection transect, Geol. Soc. Am. Bull., 97, 603-618, doi:10.1130/0016-7606(1986)97<603:TMITNB>2.0.CO;2.

Kostoglodov, V., S. K. Singh, J. A. Santiago, S. I. Franco, K. M. Larson, A. R. Lowry, and R. Bilham (2003), A large silent earthquake in the Guerrero seismic gap, Mexico, Geophys. Res. Lett., 30(15), 1807, doi:10.1029/2003GL017219.

Kruse, S., M. McNutt, J. Phipps-Morgan, L. Royden, and B. Wernicke (1991), Lithospheric extension near Lake Mead, Nevada: A model for ductile flow in the lower crust, J. Geophys. Res., 96, 4435-4456, doi:10.1029/90JB02621.

Lachenbruch, A. H., and J. A. Sass (1978), Models of an extending lithosphere and heat flow in the Basin and Range province, in Cenozoic Tectonics and Regional Geophysics of the Western Cordillera, edited by R. B. Smith and G. P. Eaton, Mem. Geol. Soc. Am., 152, 209-250.

Lee, C. T. A. (2005), Trace element evidence for hydrous metasomatism at the base of the North American lithosphere and possible association with Laramide low-angle subduction, J. Geol., 113, 673-685, doi:10.1086/ 449327.

Le Pourhiet, L., M. Gurnisa, and J. Saleeby (2006), Mantle instability beneath the Sierra Nevada mountains in California and Death Valley extension, Earth Planet. Sci. Lett., 251, 104-119, doi:10.1016/j.epsl. 2006.08.028.

Lerch, D. W., S. L. Klemperer, J. M. G. Glen, D. A. Ponce, E. L. Miller, and J. P. Colgan (2007), Crustal structure of the northwestern Basin and Range Province and its transition to unextended volcanic plateaus, Geochem. Geophys. Geosyst., 8, Q02011, doi:10.1029/2006GC001429.

Liu, Y., and J. R. Rice (2005), Aseismic slip transients emerge spontaneously in three-dimensional rate and state modeling of subduction earthquake sequences, J. Geophys. Res., 110, B08307, doi:10.1029/ 2004JB003424.

Louie, J. N., W. Thelen, S. B. Smith, J. B. Scott, M. Clark, and S. Pullammanappallil (2004), The northern Walker Lane refraction experiment: $\mathrm{P}_{\mathrm{n}}$ arrivals and the northern Sierra Nevada root, Tectonophysics, 388, 253-269, doi:10.1016/j.tecto.2004.07.042.

Lowry, A. R., and R. B. Smith (1994), Flexural rigidity of the Basin and Range-Colorado Plateau-Rocky Mountain Transition from coherence analysis of gravity and topography, J. Geophys. Res., 99, 20,12320,140, doi:10.1029/94JB00960.

Lowry, A. R., and R. B. Smith (1995), Strength and rheology of the western U.S. Cordillera, J. Geophys. Res., 100, 17,947-17,963, doi:10.1029/ 95JB00747.

Lowry, A. R., K. M. Larson, V. Kostoglodov, and R. Bilham (2001), Transient fault slip in Guerrero, southern Mexico, Geophys. Res. Lett., 28(19), 3753-3756, doi:10.1029/2001GL013238.

Luedke, R. G., and R. L. Smith (1984), Map showing distribution, composition, and age of Late Cenozoic volcanic centers in the western conterminus United States, U.S. Geol. Surv. Misc. Invest. Map, I-1525.

Machette, M. N., S. F. Personius, A. R. Nelson, D. P. Schwartz, and W. R. Lund (1991), The Wasatch fault zone, Utah-Segmentation and history of Holocene earthquakes, J. Struct. Geol., 13, 137-149, doi:10.1016/0191-8141(91)90062-N.

Maggi, A., J. A. Jackson, D. McKenzie, and K. Priestley (2000), Earthquake focal depths, effective elastic thickness, and the strength of the continental lithosphere, Geology, 28, 495-498, doi:10.1130/00917613(2000)28<495:EFDEET>2.0.CO;2.

McGeary, S., and M. R. Warner (1985), Seismic profiling the continental lithosphere, Nature, 317, 795-797, doi:10.1038/317795a0.

McKenzie, D. (1972), Active tectonics of Mediterranean region, Geophys. J. R. Astron. Soc., 30, 109-185.

McKenzie, D. (1978), Some remarks on the development of sedimentary basins, Earth Planet. Sci. Lett., 40, 25-32, doi:10.1016/0012-821X(78) 90071-7.

McQuarrie, N., and B. P. Wernicke (2005), An animated tectonic reconstruction of southwestern North America since 36 Ma, Geosphere, 1, 147-172, doi:10.1130/GES00016.1.

Melbourne, T., and D. Helmberger (2001), Mantle control of plate boundary deformation, Geophys. Res. Lett., 28, 4003-4006, doi:10.1029/ 2001 GL013167.
Melbourne, T. I., W. M. Szeliga, M. M. Miller, and V. M. Santillan (2005) Extent and duration of the 2003 Cascadia slow earthquake, Geophys. Res. Lett., 32, L04301, doi:10.1029/2004GL021790.

Miller, M. M., D. J. Johnson, T. H. Dixon, and R. K. Dokka (2001) Refined kinematics of the Eastern California shear zone from GPS observations, 1993-1998, J. Geophys. Res., 106, 2245-2263, doi:10.1029/ 2000JB900328

Miller, M. M., T. Melbourne, D. J. Johnson, and W. Q. Sumner (2002), Periodic slow earthquakes from the Cascadia subduction zone, Science, 295, 2423, doi:10.1126/science.1071193.

Molnar, P., and P. Tapponnier (1975), Cenozoic tectonics of Asia: Effects of a continental collision: Features of recent continental tectonics in Asia can be interpreted as results of the India-Eurasia collision, Science, 189, 419-426, doi:10.1126/science.189.4201.419

Niemi, N. A., B. P. Wernicke, A. M. Friedrich, M. Simons, R. A. Bennett, and J. L. Davis (2004), BARGEN continuous GPS data across the eastern Basin and Range province, and implications for fault system dynamics, Geophys. J. Int., 159, 842-862, doi:10.1111/j.1365-246X. 2004.02454.x

Okada, Y. (1992), Internal deformation due to shear and tensile faults in a half-space, Bull. Seismol. Soc. Am., 82, 1018-1040.

Oldow, J. S. (2003), Active transtensional boundary zone between the western Great Basin and Sierra Nevada block, western U.S. cordillera, Geology, 31, 1033-1036, doi:10.1130/G19838.1.

Oldow, J. S., A. W. Bally, and H. G. Avé Lallemant (1990), Transpression, orogenic float, and lithospheric balance, Geology, 18, 991-994, doi:10.1130/0091-7613(1990)018<0991:TOFALB >2.3.CO;2.

Oldow, J. S., C. L. V. Aiken, J. L. Hare, J. F. Ferguson, and R. F. Hardyman (2001), Active displacement transfer and differential block motion within the central Walker Lane, western Great Basin, Geology, 29, 19-22, doi:10.1130/0091-7613(2001)029<0019:ADTADB >2.0.CO;2.

Pancha, A., J. G. Anderson, and C. Kreemer (2006), Comparison of seismic and geodetic scalar moment rates across the Basin and Range province, Bull. Seismol. Soc. Am., 96, 11-32, doi:10.1785/0120040166.

Park, S. K., B. Hirasuna, G. R. Jiracek, and C. Kinn (1996), Magnetotelluric evidence of lithospheric mantle thinning beneath the southern Sierra Nevada, J. Geophys. Res., 101, 16,241-16,255, doi:10.1029/96JB01211.

Parsons, T., G. A. Thompson, and N. H. Sleep (1994), Mantle plume influence on the Neogene uplift and extension of the United States western Cordillera, Geology, 22, 83-86, doi:10.1130/0091-7613(1994) 022<0083:MPIOTN>2.3.CO;2.

Passchier, C. W., and R. A. J. Trouw (2005), Microtectonics, 2nd ed., 366 pp., Springer, Berlin.

Pollitz, F. F., G. Peltzer, and R. Bürgmann (2000), Mobility of continental mantle: Evidence from postseismic geodetic observations following the 1992 Landers earthquake, J. Geophys. Res., 105, 8035-8054, doi:10.1029/1999JB900380.

Potter, C. J., et al. (1987), Crustal structure of north-central Nevada: Results from COCORP deep seismic profiling, Geol. Soc. Am. Bull., 98, 330337, doi:10.1130/0016-7606(1987)98<330:CSONNR>2.0.CO;2.

Regenauer-Lieb, K., et al. (2004), On the thermodynamics of listric faults, Earth Planets Space, 56, 111-1120.

Regenauer-Lieb, K., R. F. Weinberg, and G. Rosenbaum (2006), The effect of energy feedbacks on continental strength, Nature, 442, 67-70, doi:10.1038/nature04868.

Reheis, C., and T. L. Sawyer (1997), Late Cenozoic history and slip rates of the Fish Lake Valley, Emigrant Peak, and Deep Springs fault zones, Nevada and California, Geol. Soc. Am. Bull., 109, 280-299, doi:10.1130/0016-7606(1997)109<0280:LCHASR > 2.3.CO;2.

Reston, T. J. (1990), The lower crust and the extension of the continental lithosphere: Kinematic analysis of BIRPS Deep Seismic Data, Tectonics, 9, 1235-1248, doi:10.1029/TC009i005p01235.

Roy, M., J. K. MacCarthy, and J. Selverstone (2005), Upper mantle structure beneath the eastern Colorado Plateau and Rio Grande rift revealed by Bouguer gravity, seismic velocities, and xenolith data, Geochem. Geophys. Geosyst., 6, Q10007, doi:10.1029/2005GC001008.

Rutter, E., K. Brodie, T. James, and L. Burlini (2007), Large-scale folding in the upper part of the Ivrea-Verbano zone, NW Italy, J. Struct. Geol., 29, 1 - 17, doi:10.1016/j.jsg.2006.08.013.

Saleeby, J., and Z. Foster (2004), Topographic response to mantle lithosphere removal in the southern Sierra Nevada region, Calif. Geol., 32, 245-248, doi:10.1130/G19958.1.

Saltzer, R. L., and E. D. Humphreys (1997), Upper mantle P wave velocity structure of the eastern Snake River Plain and its relationship to geodynamic models of the region, J. Geophys. Res., 102, 11,829-11,841, doi:10.1029/97JB00211.

Savage, M. K., and A. F. Sheehan (2000), Seismic anisotropy and mantle flow from the Great Basin to the Great Plains, western United States, J. Geophys. Res., 105, 13,715-13,734, doi:10.1029/2000JB900021. 
Schellart, W. P., and G. S. Lister (2005), The role of the East Asian active margin in widespread extensional and strike-slip deformation in East Asia, J. Geol. Soc., 162, 959-972, doi:10.1144/0016-764904-112.

Schellart, W. P., J. Freeman, D. R. Stegman, L. Moresi, and D. May (2007), Evolution and diversity of subduction zones controlled by slab width, Nature, 446, 308-311, doi:10.1038/nature05615.

Silver, P. G. (1996), Seismic anisotropy beneath the continents: Probing the depths of geology, Annu. Rev. Earth Planet. Sci., 24, 385-432, doi:10.1146/annurev.earth.24.1.385

Silver, P. G., and W. E. Holt (2002), The mantle flow field beneath western North America, Science, 295, 1054-1057, doi:10.1126/science.1066878.

Smith, D. (2000), Insights into the evolution of the uppermost continental mantle from xenolith localities on and near the Colorado Plateau and regional comparisons, J. Geophys. Res., 105, 16,769-16,781, doi:10.1029/2000JB900103.

Smith, D., J. C. A. Riter, and S. A. Mertzman (1999), Water-rock interactions, orthopyroxene growth, and $\mathrm{Si}$-enrichment in the mantle: Evidence in xenoliths from the Colorado Plateau, southwestern United States, Earth Planet. Sci. Lett., 165, 45-54, doi:10.1016/S0012-821X(98) 00251-9

Smith, K. D., D. von Seggern, G. Blewitt, L. Preston, J. G. Anderson, B. P. Wernicke, and J. L. Davis (2004), Evidence for deep magma injection beneath Lake Tahoe, Nevada-California, Science, 305, 1277-1280, doi:10.1126/science.1101304

Smith, R. B. (1978), Seismicity, crustal structure, and intraplate tectonics of the interior of the western Cordillera, in Cenozoic Tectonics and Regional Geophysics of the Western Cordillera, edited by R. B. Smith and G. P. Eaton, Mem. Geol. Soc. Am., 152, 111-144.

Snoke, A. W., T. J. Kalakay, J. E. Quick, and S. Sinigoi (1999), Development of a deep-crustal shear zone in response to syntectonic intrusion of mafic magma into the lower crust, Ivrea-Verbano zone, Italy, Earth Planet. Sci. Lett., 166, 31-45, doi:10.1016/S0012-821X(98)00280-5.

Sonder, L. J., and P. England (1986), Vertical averages of rheology of the continental lithosphere: Relation to thin sheet parameters, Earth Planet Sci. Lett., 77, 81-90, doi:10.1016/0012-821X(86)90134-2.

Sonder, L. J., and P. C. England (1989), Effects of a temperature-dependent rheology on large-scale continental extension, J. Geophys. Res., 94, 7603-7619, doi:10.1029/JB094iB06p07603.

Sonder, L. J., and C. H. Jones (1999), Western United States extension: How the west was widened, Annu. Rev. Earth Planet. Sci., 27, 417-462, doi:10.1146/annurev.earth.27.1.417.

Stewart, J. H. (1978), Basin-Range structure in western North America: A review, in Cenozoic Tectonics and Regional Geophysics of the Western Cordillera, edited by R. B. Smith and G. P. Eaton, Mem. Geol. Soc. Am., $152,1-31$.

Suetnova, E., R. Carbonell, and S. B. Smithson (1993), Magma in layering at the Moho of the Basin and Range of Nevada, Geophys. Res. Lett., 20 , 2945-2948, doi:10.1029/93GL02130.

Suppe, J., C. Powell, and R. Berry (1975), Regional topography, seismicity, Quaternary volcanism, and the present day tectonics of the western United States, Am. J. Sci., 275A, 397-417.

Taber, S. (1927), Fault troughs, J. Geol, 35, 577-606.

Tapponnier, P., Xu Z., F. Roger, B. Meyer, N. Arnaud, G. Wittlinger, and Yang J. (2001), Oblique stepwise rise and growth of the Tibet Plateau, Science, 294, 1671-1677, doi:10.1126/science.105978.

Thatcher, W. (1995), Microplate versus continuum descriptions of active tectonic deformation, J. Geophys. Res., 100, 3885-3894, doi:10.1029/ 94JB03064.

Thatcher, W., G. R. Foulger, B. R. Julian, J. Svarc, E. Quilty, and G. W. Bawden (1999), Present-day deformation across the Basin and Range province, western United States, Science, 283, 1714-1718, doi:10.1126/science.283.5408.1714.

Thompson, G. A., and D. B. Burke (1973), Rate and direction of spreading in Dixie Valley, Basin and Range province, Nevada, Geol. Soc. Am. Bull., 84 , 627-632, doi:10.1130/0016-7606(1973)84<627:RADOSI $>2.0$ $\mathrm{CO} \cdot 2$

Thompson, G. A., et al. (1989), Geophysics of the western Basin and Range province, in Geophysical Framework of the Continental United States, edited by L. C. Pakiser and W. D. Mooney, Mem. Geol. Soc. Am., 172 , $177-204$

Usui, T., E. Nakamura, K. Kobayashi, S. Maruyama, and H. Helmstaed (2003), Fate of the subducted Farallon plate inferred from eclogite xenoliths in the Colorado Plateau, Geology, 31, 589-592, doi:10.1130/00917613(2003)031<0589:FOTSFP $>2.0$.CO;2

Waite, G. P., D. L. Schutt, and R. B. Smith (2005), Models of lithosphere and asthenosphere anisotropic structure of the Yellowstone hot spot from shear wave splitting, J. Geophys. Res., 110, B11304, doi:10.1029/ 2004JB003501.
Walker, K. T., G. H. R. Bokelmann, and S. L. Klemperer (2004), Shearwave splitting beneath the Snake River Plain suggests a mantle upwelling beneath eastern Nevada, USA, Earth Planet. Sci. Lett., 222, 529-542, doi:10.1016/j.eps1.2004.03.024.

Wallace, R. E. (1984), Patterns and timing of Late Quaternary Faulting in the Great Basin province and relation to some regional tectonic features, J. Geophys. Res., 89, 5763-5769, doi:10.1029/JB089iB07p05763.

Wallace, R. E. (1987), Grouping and migration of surface faulting and variations in slip rates on faults in the Great Basin province, Bull. Seismol. Soc. Am., 77, 868-876.

Wang, K., T. Plank, J. D. Walker, and E. I. Smith (2002), A mantle melting profile across the Basin and Range, SW USA, J. Geophys. Res., 107(B1), 2017, doi:10.1029/2001JB000209.

Watts, A. B., and E. B. Burov (2003), Lithospheric strength and its relationship to the elastic and seismogenic layer thickness, Earth Planet. Sci. Lett., 213, 113-131, doi:10.1016/S0012-821X(03)00289-9.

Weinberg, R. F., K. Regenauer-Lieb, and G. Rosenbaum (2007), Mantle detachment faults and the breakup of cold continental lithosphere, Geology, 35, 1035-1038, doi:10.1130/G23918A.1

Wernicke, B. (1985), Uniform-sense normal simple shear of the continental lithosphere, Can. J. Earth Sci., 22, 108-125.

Wernicke, B. (1990), The fluid crustal layer and its implications for continental dynamics, in Exposed Cross Sections of the Continental Crust, edited by M. H. Salisbury and D. M. Fountain, pp. 509-544, Kluwer Acad., Dordrecht, Netherlands.

Wernicke, B. (1992), Cenozoic extensional tectonics of the Cordillera, U.S. in The Geology of North America, vol. G3, The Cordilleran Orogen: Conterminus U.S., edited by B. C. Burchfiel et al., pp. 553-581, Geol. Soc. of Am., Boulder, Colo.

Wernicke, B., et al. (2000), Dynamics of plate boundary fault systems from Basin and Range Geodetic Network (BARGEN) and geologic data, GSA Today, 10, 1-7.

Wernicke, B., J. L. Davis, R. A. Bennett, J. E. Normandeau, A. M. Friedrich, and N. A. Niemi (2004), Tectonic implications of a dense continuous GPS velocity field at Yucca Mountain, Nevada, J. Geophys. Res., 109, B12404, doi:10.1029/2003JB002832.

Wesnousky, S. G. (2005a), The San Andreas and Walker Lane fault systems, western North America: Transpression, transtension, cumulative slip and the structural evolution of a major transform plate boundary, J. Struct. Geol., 27, 1505-1512, doi:10.1016/j.jsg.2005.01.015.

Wesnousky, S. G. (2005b), Active faulting in the Walker Lane, Tectonics, 24, TC3009, doi:10.1029/2004TC001645.

Wesnousky, S. G., A. D. Barron, R. W. Briggs, S. J. Caskey, S. Kumar, and L. Owen (2005), Paleoseismic transect across the northern Great Basin, J. Geophys. Res., 110, B05408, doi:10.1029/2004JB003283.

Wilson, D., R. Aster, J. Ni, S. Grand, M. West, W. Gao, W. S. Baldridge, and S. Semken (2005), Imaging the seismic structure of the crust and upper mantle beneath the Great Plains, Rio Grande Rift, and Colorado Plateau using receiver functions, J. Geophys. Res., 110, B05306, doi:10.1029/2004JB003492.

York, J. E., and D. V. Helmberger (1973), Low velocity zone variations in the southwestern United States, J. Geophys. Res., 78, 1883-1886, doi:10.1029/JB078i011p01883.

Zandt, G., and E. Humphreys (2008), Toroidal mantle flow through the western U.S. slab window, Geology, 36, 295-298, doi:10.1130/ G24611A.1.

Zandt, G., S. C. Myers, and T. C. Wallace (1995), Crust and mantle structure across the Basin and Range-Colorado Plateau boundary at $37^{\circ} \mathrm{N}$ latitude and implications for Cenozoic extensional mechanism, J. Geophys. Res., 100, 10,529-10,548, doi:10.1029/94JB03063.

Zandt, G., H. Gilbert, T. J. Owens, M. Ducea, J. Saleeby, and C. H. Jones (2004), Active foundering of a continental arc root beneath the southern Sierra Nevada in California, Nature, 431, 41-46, doi:10.1038/ nature 02847.

S. Bisnath, Department of Earth and Space Science and Engineering, York University, 4700 Keele Street, Toronto, ON M3J 1P3, Canada.

J. L. Davis, Harvard-Smithsonian Center for Astrophysics, 60 Garden Street, MS 42, Cambridge, MA 02138, USA

P. Luffi, Department of Earth Science, Rice University, Earth Science MS-126, 6100 Main Street, Houston, TX 77005-0000, USA.

N. A. Niemi, Department of Geological Sciences, University of Michigan, 1100 North University Avenue, 2534 CC Little Building, Ann Arbor, MI 48109-0000, USA.

B. Wernicke, Division of Geological and Planetary Sciences, California Institute of Technology, Sciences 170-25, 1200 East California Boulevard, Pasadena, CA 91125, USA. (brian@gps.caltech.edu) 